Review Article

\title{
Vitamin C in Stem Cell Biology: Impact on Extracellular Matrix Homeostasis and Epigenetics
}

\author{
Cristina D'Aniello, Federica Cermola, Eduardo Jorge Patriarca, and Gabriella Minchiotti \\ Stem Cell Fate Laboratory, Institute of Genetics and Biophysics 'A. Buzzati-Traverso', CNR, 80131 Naples, Italy \\ Correspondence should be addressed to Eduardo Jorge Patriarca; eduardo.patriarca@igb.cnr.it and Gabriella Minchiotti; \\ gabriella.minchiotti@igb.cnr.it
}

Received 29 December 2016; Accepted 5 March 2017; Published 20 April 2017

Academic Editor: Alfredo Garcia

Copyright (c) 2017 Cristina D'Aniello et al. This is an open access article distributed under the Creative Commons Attribution License, which permits unrestricted use, distribution, and reproduction in any medium, provided the original work is properly cited.

Transcription factors and signaling molecules are well-known regulators of stem cell identity and behavior; however, increasing evidence indicates that environmental cues contribute to this complex network of stimuli, acting as crucial determinants of stem cell fate. L-Ascorbic acid (vitamin $\mathrm{C}(\mathrm{VitC})$ ) has gained growing interest for its multiple functions and mechanisms of action, contributing to the homeostasis of normal tissues and organs as well as to tissue regeneration. Here, we review the main functions of $\mathrm{VitC}$ and its effects on stem cells, focusing on its activity as cofactor of $\mathrm{Fe}^{+2} / \alpha \mathrm{KG}$ dioxygenases, which regulate the epigenetic signatures, the redox status, and the extracellular matrix (ECM) composition, depending on the enzymes' subcellular localization. Acting as cofactor of collagen prolyl hydroxylases in the endoplasmic reticulum, VitC regulates ECM/collagen homeostasis and plays a key role in the differentiation of mesenchymal stem cells towards osteoblasts, chondrocytes, and tendons. In the nucleus, VitC enhances the activity of DNA and histone demethylases, improving somatic cell reprogramming and pushing embryonic stem cell towards the naive pluripotent state. The broad spectrum of actions of VitC highlights its relevance for stem cell biology in both physiology and disease.

\section{Introduction}

L-Ascorbic acid (vitamin C (VitC)) was extensively studied over the last century because it plays an essential role for proper folding and deposition of collagen proteins, which are the most abundant proteins in the human body and have a strong impact on the composition/structure/biomechanical features of the extracellular matrix (ECM). Human cells are unable to synthesize VitC, and therefore, it must constantly be restored through the diet. Indeed, under VitC deprivation, human cells are unable to generate and maintain healthy tissues, in particular those rich in collagens such as the skin, bones, and cartilage, and VitC deficiency in humans causes scurvy, a complex syndrome characterized by generalized ECM dissolution and tissue disintegration. It is only until recently that ECM homeostasis was considered the unique molecular mechanism influenced by VitC availability. In the last years, the use of cutting-edge technologies (nextgeneration sequencing and advanced microscopy) to study stem cell biology have broadened enormously our knowledge of VitC activities. Specifically, VitC has emerged as a key regulator of stem cell identity/behavior, influencing pluripotency, self-renewal, and differentiation. VitC enhances somatic cell reprogramming, that is, the generation of induced pluripotent stem cells (iPSCs), and pushes embryonic stem cells toward a naive state of pluripotency by modulating the cellular epigenetic profile [1-3]. The strong biological, biotechnological, and medical significance of VitC-dependent molecular mechanisms become even more relevant taking into account another key VitC-dependent cellular modification, that is, collagen hydroxylation, which is the most abundant posttranslation modification found in the human proteoma. In this review, we will focus on the recent progress made on the influence of VitC on stem cell biology and its implications for regenerative medicine.

\section{Vitamin C Metabolism and Functions}

VitC is a naturally occurring small carbohydrate (3-keto-Lgulofuranlactone) synthesized by a two-step reaction mainly 


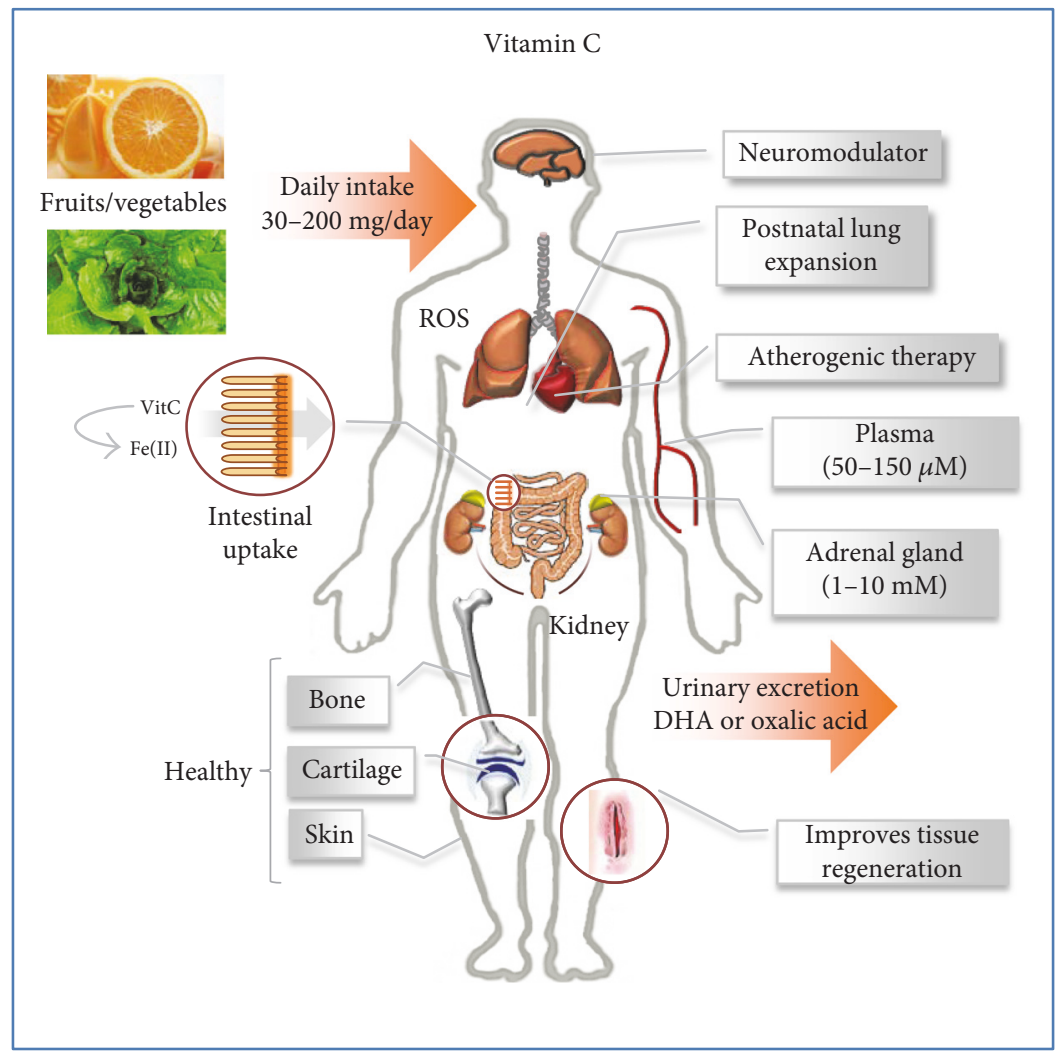

FIGURE 1: Vitamin C metabolism and activities. Vitamin C, in humans, must be introduced by daily intake through diet. It plays crucial roles both for the proper function of healthy organs and tissues and for tissue repair and regeneration. VitC may act as a scavenger against reactive oxygen species (ROS) and as a chelator, for example, iron metabolism. Both VitC and its catabolic product, dehydroascorbate (DHA), are excreted through urine.

from L-galactose or D-galacturonic acid in green plants [4]. Humans are unable to synthesize VitC due to the lack of the L-gulonolactone oxidase (GLO) enzyme and therefore are strictly dependent on an exogenous source of VitC. Its level is maintained in a range between micromolar in the blood plasma $(\sim 50 \mu \mathrm{M})$ and millimolar $(\sim 1-10 \mathrm{mM})$ inside the cells (Figure 1), with the highest levels found in pituitary and adrenal gland cells where it is accumulated through the activity of highly specific transport systems encoded by the SLC23A1 and SLC23A2 genes, also known as SVCT1 and SVCT2 [5-7]. VitC is continuously catabolized by oxidation to dehydroascorbate (DHA), which in turn is converted into oxalic acid [8]. The main route of elimination of $\mathrm{VitC}$ and DHA is urinary excretion (Figure 1). Oxalate is one of the major end products of VitC breakdown in humans, and this may cause accumulation of calcium oxalate stones and nephrocalcinosis; thus, susceptible people should avoid systematic ingestion of vitamin C supplements [9].

2.1. ROS Neutralizer and Iron Chelator. VitC is considered the most relevant naturally occurring reducing substance [10]. Inside the cells, VitC cooperates to maintain the intracellular redox balance. $\mathrm{VitC}$ reduces reactive oxygen species (ROS), including superoxide anion $\left(\mathrm{O}_{2}^{-1}\right)$, hydroxyl radical $\left(\mathrm{OH}^{-}\right)$, singlet oxygen $\left(\mathrm{O}_{2}{ }^{*}\right)$, and hypochlorous acid $(\mathrm{HClO})$, which are generated during mitochondrial oxidative phosphorylation (aerobic ATP generation). ROS regulate several signaling pathways involved in pluripotency, including MAPKs, ERKs, p38MAPKs, JNKs, and MAPK phosphatases. Interestingly, VitC inhibits $\mathrm{NFkB}$ activation in human cell lines (U937, HL-60, and MCF-7) and in primary cells (HUVEC) in a dose-dependent manner [11]. ROS inactivation results in VitC oxidation to dehydroascorbic acid (DHA), which in turn alters cellular homeostasis. DHA can be reduced to $\mathrm{VitC}(\mathrm{DHA} \rightarrow \mathrm{VitC}$ ) by enzymatic and nonenzymatic activities involving glutathione and homocysteine, which regenerate/recycle VitC $[12,13]$. Besides its role as antioxidant, VitC exerts a chelator activity; indeed, by reducing ferric to ferrous $\left(\mathrm{Fe}^{+3} \rightarrow \mathrm{Fe}^{+2}\right.$ ) iron and by generating soluble iron complexes, VitC efficiently enhances the absorption of nonheme iron at the intestine level [14-17]. The chromaffin granule cytochrome $b_{561}\left(\right.$ CGCyt $b_{561}$ ) and the duodenal Cyt $b_{561}\left(\right.$ DCyt $\left.b_{561}\right)$ are transmembrane oxidoreductases $[18,19]$, which contribute to recycle VitC from DHA and enhance iron absorption. Indeed, while CGCyt $\mathrm{b}_{561}$ catalyzes the transfer of electrons from cytoplasmic VitC to intravesicular DHA (DHA $\rightarrow$ VitC), DCyt $b_{561}$ transfers electrons from cytoplasmic $\mathrm{VitC}$ to $\mathrm{Fe}^{+3}$ ions in the intestinal lumen, thus generating soluble $\mathrm{Fe}^{+2}$ ions which are eventually taken up by the cells through a $\mathrm{Fe}^{2+}$ transporter [20, 21]. As recently reviewed [22], VitC impacts on iron metabolism also stimulate ferritin synthesis, inhibit lysosomal ferritin degradation and cellular iron efflux, and induce iron uptake from low-molecular weight iron-citrate complexes. 


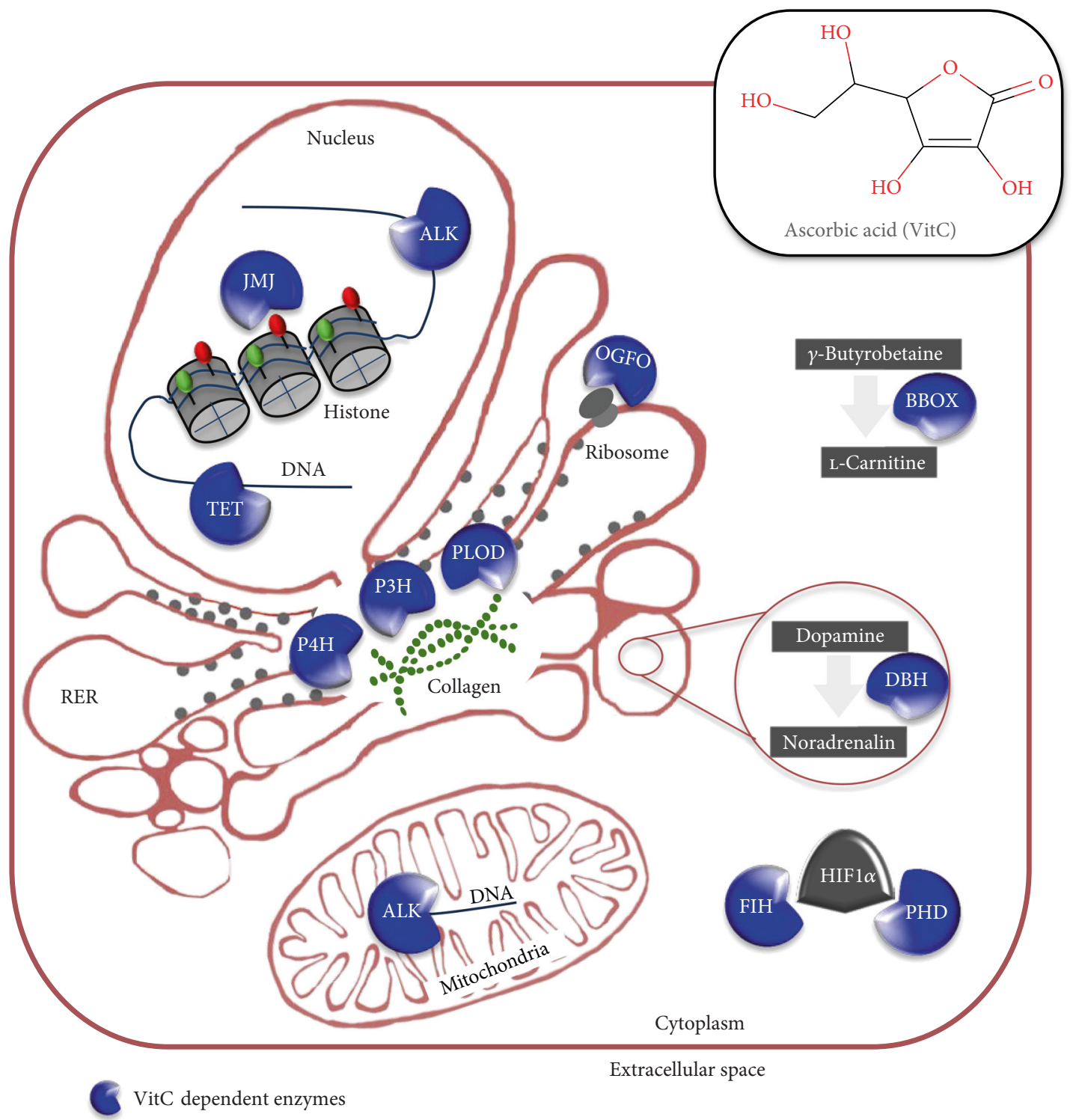

FIGURE 2: Localization and functions of VitC-dependent mono- and dioxygenase enzymes. ALK: RNA and DNA demethylase family; JMJ: jumonji histone demethylases; TET: ten-eleven translocation DNA demethylases; OGFO: 2-oxoglutarate- and Fe ${ }^{2+}$-dependent oxygenase; PLOD: procollagen-lysine_ $\alpha$-KG_5-dioxygenases; P3H: collagen prolyl 3-hydroxylase; $\mathrm{P} 4 \mathrm{H}$ : collagen prolyl 4-hydroxylases; BBOX1: $\gamma$-butyrobetaine dioxygenases; DBH: dopamine beta-monooxygenase; PHD: HIF-prolyl hydroxylase; FIH: factor inhibiting HIF.

2.2. Enzymatic Cofactor/Enhancer. Besides its role as antioxidant, VitC is essential for the activity of a family of mono- and dioxygenases enzymes (EC 1.14.11) by providing the electrons required to keep the prosthetic metal ions in the reduced/active form, specifically $\mathrm{Cu}^{+1}$ (cuprous) for the monoxygenases and $\mathrm{Fe}^{+2}$ (ferrous) for the dioxygenases $[23,24]$. In mammals, VitC-dependent oxygenases catalyze the hydroxylation of DNA, peptides/proteins, and lipids as well as a wide variety of small molecules. For instance, $\mathrm{VitC}$ is the cofactor of the $\gamma$-butyrobetaine dioxygenase (BBOX1), which catalyzes the final step of L-carnitine biosynthesis (Figure 2). This enzyme is involved in the transport of fatty acids inside the mitochondria for $\beta$-oxidation and modulates osteogenesis and chondrogenesis in adiposeand bone marrow-derived stem cells [25]. Similarly, VitC is required for the conversion of the neurotransmitter dopamine to noradrenalin (dopamine beta-monooxygenase $(\mathrm{DBH})$ ), the metabolism of tyrosine and the amidation of peptide hormones. VitC-dependent enzymes also include the prolyl hydroxylases that regulate the hydroxylation and thus the degradation of the hypoxia-inducible factor (HIF). Conversely, 5-(hydroxymethyl)-2-furfural (5-HMF) stabilizes HIF protein by reducing VitC level [26]. Of note, VitC enhances the activity of the asparaginyl hydroxylase factor inhibiting HIF-1 (FIH-1), which is an important suppressor of hypoxia-inducible factor (HIF) activity [27]. Interestingly, HIF regulates stem cell pluripotency and self-renewal controlling specific signaling pathways and transcription factors [28]. Most remarkably, VitC enhances the activity of a specific class of RNA and/or DNA demethylases, that is, the human AlkB homologue enzymes ( $\mathrm{VitC} / \mathrm{Fe}^{+2} / \alpha \mathrm{KG}$ dependent dioxygenases) [29, 30], including $\mathrm{ABH} 1$ (or 
ALKBH1), which catalyzes the demethylation of 3-meC in DNA and RNA [31]; ABH2 (ALKBH2), which catalyzes the oxidative demethylation of 1-methyladenine [32]; $\mathrm{ABH} 3$ (ALKBH3), which repairs methylated RNA [33]; and FTO, which demethylates 3-methylthimidine (3-meT) and 3-methyluracil [34], whose variants were found associated with obesity in both children and adults [35]. Another class of $\mathrm{VitC} / \mathrm{Fe}^{+2} / \alpha \mathrm{KG}$-dependent demethylases has recently gained great attention, due to their key role in somatic cell reprogramming, specifically, the jumonji (JHDM, KDM) family, which are engaged in histone demethylation (chromatinmodifying oxygenases) and the DNA demethylases of the ten-eleven translocation (TET) family [36-40]. Finally, the P4HA and PLOD enzymes belong to the same family of $\mathrm{VitC} / \mathrm{Fe}^{+2} / \alpha \mathrm{KG}$-dependent dioxygenases and catalyze the hydroxylation of collagen proline and lysine residues. Thus, VitC activity is essential for the activity of key epigenetic enzymes as well as for the conversion of procollagen to collagen. Moreover, it has recently been reported that VitC stimulates the iron-mediated nonenzymatic conversion of the oncometabolite $\alpha$-hydroxyglutarate (2-HG) into $\alpha$ ketoglutarate [41]. $2 \mathrm{HG}$ is a competitive inhibitor of $\alpha$-ketoglutarate dioxygenases [42]. Therefore, VitC influences the epigenetic signature, the metabolism (fatty acid catabolism), and the microenvironment (collagen/ECM composition) of the cells, thus pointing to a key role of VitC availability in shaping cell identity/behavior.

2.3. VitC Localization. By acting as antioxidant, VitC is required in all the subcellular compartments but particularly inside the oxidative organelles (mitochondria, endoplasmic reticulum, and peroxisomes). Indeed, by acting as an enzymatic cofactor, its requirement depends on the enzymes' subcellular localization (Figure 2). For instance, histone and DNA demethylases are all located in the nucleoplasm. Specifically, AlkB human homologues (ALBH or ALKBH enzymes) are located in the nucleoplasm and inside the mitochondria where they catalyze the demethylation of 3-meC residues on DNA and RNA, respectively [31]. Collagen prolyl/lysyl hydroxylases are localized in the ER lumen [43], HIF prolyl hydroxylases (PHDs) in the cytosol, and dopamine $\beta$-monooxygenase and peptidylglycine $\alpha$-hydroxylating monooxygenase (PHM) in the synaptic and secretory vesicles. Since VitC is a water-soluble molecule, specific transport systems should be activated to keep optimal VitC concentrations in each subcellular compartment. Two families of transporters are associated with VitC transport in human cells, the sodium- $\left(\mathrm{Na}^{+1}-\right)$ coupled ascorbic acid transporters (SVCTs; SLC23), which are highly specific for reduced $\mathrm{VitC}$, and the members of the glucose transporter (GLUT; SLC2) family, some of which also transport DHA. SVCT2 transporter colocalizes with the protein disulfide isomerase (PDI) and marks both ER and mitochondrial membranes. Interestingly, the embryonic brain cortex of SVCT2 KO mouse mutants produces significant lower levels of several neurotransmitters, including dopamine and norepinephrine [44] and, furthermore, SVCT2 knockdown mitochondria inefficiently transport VitC [45]. Finally, homozygous Slc23a1 ${ }^{-1-}$ mice die at birth with respiratory failure and intraparenchymal brain hemorrhage [46]. SLC23A1 is essential for renal reabsorption and hepatic accumulation of VitC but not for its intestinal transport [47]. Interestingly, specific polymorphisms in the sodiumdependent VitC transporter 2 gene increase the risk of incident of acute coronary syndrome in women, but not in man [48]. So far, the transporters that facilitate VitC accumulation in the intraluminal ER have not been characterized at a molecular level. However, defects in the subcellular distribution of VitC may cause diseases and aging. For instance, impaired mitochondrial uptake of VitC/DHA and thus a VitC shortage in the mitochondrial matrix should provoke a defective removal of ROS. Indeed, it has recently been hypothesized that VitC may be channelled from the nucleoplasm to the ER lumen through the ER subdomain nuclear envelope [43], which may eventually reduce the level of VitC in the nucleus and thus its availability for the epigenetic enzymes. A similar subcellular redistribution of $\mathrm{VitC}$ may occur as a consequence of a rapid and massive accumulation of collagen synthesis, for instance upon stimulation with transforming growth factor- $\beta$ (TGF $\beta$ ). Thus, it is interesting to hypothesize that changes in VitC levels in the different subcellular compartments could impact on the redox status, the epigenetic signature, and the ECM composition and eventually modify cell behavior. In this respect, it is important to take into account that VitC subcellular distribution likely depends on the expression levels and binding affinities of the different VitC-dependent enzymes and carriers; however, our knowledge is still limited and this issue needs to be further studied [43].

\section{VitC-Dependent Regulation of ECM/Collagen Homeostasis}

The extracellular matrix (ECM) is a complex mix of fibrillar proteins and polysaccharides synthesized and secreted by the cells in the extracellular space. Indeed, with the exception of the neural extracellular matrix [49], the ECM has a fibrillar structure in most tissues and provides a structural scaffold to the surrounding cells that is essential for tissue/organ morphogenesis, as well as for their regeneration after injury. Collagens are the most abundant proteins in the ECM and thus the most abundant proteins in mammals ( $30 \%$ of total protein mass) [50] making up 90\% of the bone tissue [51]. Collagens are crucial for the development and maintenance of the skin, cartilage, tendons, ligaments, and of the blood vessels and are deposited in the ECM where they generate supramolecular assemblies/complexes contributing to the shape and mechanical properties of tissues, such as the tensile strength in the skin and the ligament resistance to traction [52]. VitC thus impacts on ECM homeostasis by regulating collagen synthesis and maturation.

3.1. Collagen Synthesis. VitC promotes the transcription of collagen genes and/or increases the stability of collagen mRNA in many different cell lines, including human skin fibroblasts [53, 54], PAT cells [55], and murine 3T3-L1 preadipocytes [56]. Also, profibrotic cytokines of the TGF $\beta$ family stimulate collagen synthesis, especially in wound 
healing and fibrotic diseases [57]. Interestingly, activation of the TGF $\beta$ pathway enhances collagen synthesis and reduces collagen degradation in different cell lines, including human mesenchymal stem cells [58], human marrow stromal cell [59], human dermal fibroblasts [60-62], glomerular mesangial cells [63], lung alveolar epithelial cells [64], and vascular smooth muscle cells (VSMCs) [65], thus resulting in fibrosis/ECM accumulation. In line with these findings, in human dermal fibroblasts, several collagen-coding genes, including COL1A2, COL3A1, COL6A1, and COL6A3, have been identified as TGF $\beta /$ SMAD3 targets in human dermal fibroblasts [66]. Moreover, vitamin D-induced reduction of intestinal fibrosis has been associated with the inhibition of the canonical TGF $\beta /$ SMAD3 pathway [67]. In renal epithelial cells, TGF $\beta$ regulates collagen deposition by recruiting mTOR kinase (through noncanonical TGF $\beta$ pathway) [47, 68]. Interestingly, mTOR regulates HIF- $1 \alpha$, which in turn is controlled by VitC and regulates the transcription of COL1A2 (collagen I $\alpha 2$ ) gene. Indeed, knockdown of DEPTOR, an mTOR signaling inhibitor, induces collagen expression; conversely knockdown of RAPTOR, which conversely is a positive regulator of $\mathrm{mTOR}$, inhibits collagen expression. TGF $\beta$ can increase collagen synthesis also by inducing the cleavage of the cAMP response element-binding protein 3like 1 (CREB3L1) transcription factor [69]. Of note, collagen synthesis may be induced also independently of the TGF $\beta$ signaling as described during hypoxia-dependent mesenchymalization of human lung epithelial A549 cell line [70].

3.2. Collagen Prolyl and Lysyl Hydroxylases. Collagens are synthesized as procollagen molecules, which are subjected to numerous posttranslational modifications, that is, hydroxylation of L-pro and L-lys residues, glycosylation of L-lys and hydroxylysine residues, and sulfation of tyrosine (Tyr) residues (see [71]). Collagen synthesis also requires the activity of specific posttranslational enzymes that are inactivated by the formation of the collagen triple helix. First, collagen hydroxylation is required for the correct folding of procollagen polypeptide chains into stable triple helical molecules. Collagen lysyl hydroxylases, also known as procollagenlysine_ $\alpha-K G$ - 5-dioxygenases, encoded by PLOD1, PLOD2, and PLOD3 genes, are VitC-dependent enzymes that catalyze the lysine hydroxylation [72, 73]. Collagen prolyl 4-hydroxylases ( $\mathrm{P} 4 \mathrm{Hs}$ ) are $\mathrm{VitC}$-dependent enzymes that catalyze the proline hydroxylation in collagens. Collagen prolyl hydroxylation involves three isoforms of the P4HA subunit (P4HA1, P4HA2, and P4HA3) that form $\mathrm{A}_{2} \mathrm{~B}_{2}$ tetramers with $\mathrm{P} 4 \mathrm{HB}$ and eventually $\mathrm{P} 4 \mathrm{H} 1, \mathrm{P} 4 \mathrm{H} 2$, and $\mathrm{P} 4 \mathrm{H} 3$ holoenzymes, respectively. Collagen prolyl hydroxylation is the major posttranslational modification in the human proteoma [74]. In the absence of $\mathrm{P} 4 \mathrm{H}$ activity, the procollagen molecules are unable to exit the ER $[75,76]$. Interestingly, it has been previously reported that $\mathrm{PH}$ activity is induced early during wound healing and that its induction is associated with the onset of collagen biosynthesis and deposition [77]. Increasing evidence suggest that VitC-dependent collagen hydroxylation positively correlates with tumor aggressiveness. Recently, it has been shown that silencing of P4HA2 (collagen prolyl 4-hydroxylase $\alpha$ subunit 2) expression inhibits proliferation and suppresses the most aggressive phenotype of breast cancer cells in vivo [78]. Of note, treatment with the $\mathrm{P} 4 \mathrm{H}$ inhibitor ethyl 3,4-dihydroxybenzoate induces a similar phenotype [79]. Interestingly, P4HA1 is highly expressed in aggressive prostate cancer and it is essential for in vivo cancer progression [80].

3.3. Collagen Signaling. Collagen precursors (procollagen/ $\sim 300$ nanometers in length) are synthesized in the endoplasmic reticulum (ER), packaged into transport vesicles, and delivered to Golgi cisternae where fibrillogenesis occurs. The resulting collagen fibrils are the longest (up to millimeters in length) and the largest protein polymers in vertebrates $[51,81]$. Collagens are degraded in the extracellular microenvironment through the activity of zinc-dependent endopeptidases, that is, the matrix metalloproteinases (MMPs), which are the key enzymes involved in physiological (development and tissue repair) and pathological (tumorigenesis and metastasis) processes [82]. Collagens participate in cellmatrix interactions acting as functional ligands of several receptor families including glycoprotein VI (GPVI), inhibitory leukocyte-associated immunoglobulin-like receptor-1 (LAIR-1), Endo180 (urokinase-type plasminogen activatorassociated protein), integrins, and dimeric discoidin receptors (DDR1 and DDR2) [83-85]. Of note, DDR receptors are powerful inhibitors of collagen deposition (fibrillogenesis) [86]. These collagen-receptor interactions modulate cell growth, differentiation, and migration. Of note, $\beta(1)$ integrins are required for correct embryoid body formation and cardiac fate specification and differentiation of induced pluripotent stem cells [87].

3.4. Influence of ECM in Tissue Generation, Regeneration, and Cancer. VitC influences ECM composition/structure, and it is now evident that the mechanical features of the ECM influence normal and cancer stem cell behavior [88-93]. For instance, while soft substrates $(0.6 \mathrm{kPa}$ polyacrylamide gels coated with of type-1 collagen) sustain embryonic stem cell (ESC) self-renewal [94], rigid/stiff substrates induce differentiation/lineage specification of mesenchymal stem cells (MSCs) [95]. ECM structure also impacts on tumor cells' behavior. Indeed, breast cancer malignancy is associated with ECM stiffening [88], and increased collagen deposition and collagen fiber diameter, through ROCK activation, drive epidermal hyperplasia [90]. Interestingly, VitC-dependent collagen prolyl and lysyl hydroxylases are key regulators of breast cancer metastasis [79, 96, 97]. In particular, HIF-1-mediated induction of VitC-dependent PLOD2 enzyme is required for deposition of fibrillar collagen and increase tumor stiffness [96]. Recently, the use of soft fibrin gels allowed the isolation of a subpopulation of highly tumorigenic melanoma cancer cells, named tumorrepopulating cells (TRCs) [98]. Of note, TRC self-renewal relies on a specific epigenetic modification, that is, VitCdependent demethylation of the histone 3 lysine 9 (H3K9) [99]. Indeed, silencing of H3K9 demethylases inhibits TRC self-renewal [99].

Besides its involvement in tumor cell progression, it is well known that ECM is a key determinant within the stem 
cell niche, influencing also normal stem cell behavior and identity. Indeed, several signals and factors produced by the ECM have been reported to integrate with other signaling pathways and transcription factors, thus finely modulating stem cell proliferation, self-renewal, and cell fate decisions both in vitro and in vivo. In particular, integrin receptors respond to ECM signals, regulating stem cell differentiation in early embryogenesis. Indeed, integrin $\beta 1$ is essential for inner-cell mass development [100], and laminin-deficient embryos are unable to undergo epiblast differentiation and cavitation [101]. In line with these findings, type-1 collagen (collagen-1) facilitates mESC self-renewal in vitro [102]. Moreover, VitC-dependent collagen synthesis is essential for the induction of ESC cardiac differentiation, which in turn is impaired by two inhibitors of collagen synthesis (1-2-azetidine carboxylic acid and cis-4-hydroxy-d-proline) [103]. Of note, ECM signaling also influences self-renewal of various somatic stem cells, safeguarding epidermal stem cell compartment [104], neural stem cell maintenance and behavior [105], and hematopoietic stem cell self-renewal and differentiation [106]. Furthermore, ECM is crucial for the skeletal system development, function, and repair, impacting on different stem cell types such as osteoblasts/osteoclasts involved in bone remodeling [107] and mesenchymal stem cells [108], chondrocytes and tenocytes [109], and muscle stem cells (for a review, see [110]). Based on these observations, VitC availability might influence stem cell phenotype/ behavior by regulating ECM stiffness and homeostasis and thus playing a crucial role for tissue function.

\section{VitC as Epigenetic Modifier}

Epigenetic changes are important regulators of gene expression both in development and in diseases. Among them, addition of a methyl group to the C5 position of cytosine on DNA and to the lysine at different positions (K4, 9, 27, and 36) of histone $3(\mathrm{H} 3)$ represents the major and best characterized epigenetic modification. VitC impacts the epigenetic signature of the cells by promoting the activity of the $\mathrm{Fe}^{2+}$ and $\alpha \mathrm{KG}$-dependent dioxygenases involved in DNA and histone demethylation.

4.1. VitC and DNA Demethylation. DNA methylation is catalyzed by DNA methyltransferases (DNMTs) and plays a pivotal role in modulating transcription activity and cellular identity. In mammals, it mostly involves the cytosine residues of CpG dinucleotides. Global DNA demethylation occurs early during embryo development, at the preimplantation stages, that is, before the inner cell mass (ICM) specification $[111,112]$. Conversely, a widespread DNA remethylation occurs during gastrulation and leads to lineage restriction and loss of pluripotency. Aberrant DNA methylation is a hallmark of cancer $[113,114]$, and global DNA hypomethylation is associated with poor prognosis in tumor patients [115]. Global changes in DNA methylation patterns have been associated with cardiovascular diseases, essential hypertension, inflammation, autoimmune diseases, and infections [116-120]. DNA demethylation depends on the catalytic activity of the $\mathrm{VitC} / \mathrm{Fe}^{+2} / \alpha \mathrm{KG}$-dependent TET (ten-eleven translocation) enzymes, which convert 5-methylcytosine (5-mC) into 5-hydroxymethylcytosine (5-hmC). A further TET-mediated oxidation of 5-hmC to 5-formylcytosine (5-fC) and to 5-carboxylcytosine (5-caC), together with the activation of the base excision repair mechanism, lead to a complete demethylation process [38]. Of note, blocking VitC entry into the cells by phloretin and/or preventing (knocking down) the expression of Tet genes (Tet1, Tet2, and Tet3) by short interference RNAs (siRNA) significantly reduces VitC-dependent 5-hmC induction [121]. Moreover, treatment of cells with glutathione, an antioxidant agent, does not alter the level of 5-hmC; thus, indicating that VitCdependent induction of $5-\mathrm{hmC}$ is not due to its activity as an antioxidant, thus supporting a key role of $\mathrm{VitC}$ as a cofactor for TET DNA dioxygenases. Interestingly, in hepatocellular carcinoma cells, VitC enhances the demethylating effect of 5-Azacytidine (a DNA methyl transferase inhibitor), inducing the expression/activity of Tet enzymes and increasing the levels of 5-hmC [122].

4.2. VitC and Histone Demethylation. The transfer of a methyl group to lysine and arginine residues of histone proteins is the principal epigenetic modification that occurs on histones and is part of the epigenetic mechanisms that controls stem cell homeostasis. This reaction is catalyzed by histone methyltransferases, which, as DNMTs, use $\mathrm{S}$-adenosylmethionine as donor of methyl groups. While for DNA methylation, only one methyl group is added to cytosine, for histones, up to three or two methyl groups can be added to lysine and arginine, respectively. The resulting mono-, di-, and trimethylated residues can either promote or silence chromatin, depending on the methylated residue. As for DNA methylation, also histone methylation is a reversible process, which depends on the activity of histone demethylases, such as the $\mathrm{VitC} / \mathrm{Fe}^{+2} / \alpha-\mathrm{KG}$ dependent demethylases, that is, the JmjC domain-containing histone demethylases. Thus, VitC enhances the activity of several JmjC domain-containing histone demethylases, inducing histone demethylation and contributing to establish the epigenetic signature of the cells. For instance, VitC counteracts $\mathrm{H} 3 \mathrm{~K} 9$ and $\mathrm{H} 3 \mathrm{~K} 36$ and DNA methylation induced by exogenously provided L-Proline in ESCs [123].

4.3. VitC-Dependent Dioxygenases in Stemness, Fibrosis, and Cancer. VitC availability has been reported to be crucial for stem cell identity and plasticity. Increased VitC availability $(100 \mu \mathrm{g} / \mathrm{ml})$ in mouse ESCs promotes widespread DNA demethylation through TET activity [3] and pushes ESCs towards a naive state of pluripotency, which can be placed between the naive/2i and FBS/LIF cultures [1]. VitC induces extensive DNA hypomethylation also in human embryonic stem cells (hESCs) [124]. VitC maintains the methylated pattern and regulates the expression of the imprinted Dlk1-Dio3 cluster in ESCs and acquisition of full pluripotency [125]. Indeed, VitC promotes TET activity (DNA demethylation) and enhances the generation of mouse and human-induced pluripotent stem cells (iPSCs) leading to the transcriptional activation of pluripotency gene network [121, 126, 127]. Similarly, VitC promotes histone 
demethylation, reducing the level of $\mathrm{H} 3 \mathrm{~K} 9 \mathrm{me} 3$ and enhancing the pre-iPSC to iPSC transition [2, 128, 129]. Accordingly, mouse embryonic fibroblasts (MEFs) upon $\mathrm{KD}$ of the Tet enzymes fail to undergo the mesenchymal to epithelial transition necessary for the reprogramming process $[128,130,131]$. In line with these findings, VitC activity exerts a key role in the early stages of embryo development, as suggested by several developmental defects induced by VitC deficiency. Indeed, although the knowledge of the mechanism is still limited, several evidence indicate a key role of VitC-dependent activity of DNA and histone demethylases during early embryonic development. Indeed, VitC-induced Tet3 activity is required for epigenetic reprogramming of the zygotic paternal DNA and for the subsequent demethylation of the maternal DNA [132]. Moreover, VitC promotes a second round of demethylation in primordial germ cells (PGC) [133].

Epigenetic changes induced by VitC are important modulators of cell identity and are also considered hallmarks of several pathological conditions. In particular, different types of cancers, including leukemia, melanoma, colorectal adenoma, and gastric cancers, show reduced levels of 5-hmC, which may alter the normal regulation of gene expression and lead to malignant transformation. Interestingly, mutations that result in decreased expression and/or altered function of TET enzymes, as well as mutations in SVCT genes that reduce the normal uptake of VitC and thus the level of 5 -hmC, have been described in human cancers $[134,135]$. Interestingly, restoring the levels of 5-hmC could at least in part decrease malignancies [134]. While the role of epigenetic alterations, that is, reduced 5 -hmC levels, has been mostly implicated and studied in cancers, their relevance in other diseases remains still poorly understood. A growing interest is emerging in the context of fibrotic diseases. Although different studies support the idea that the acquisition of the profibrotic characteristics in different pathologies is associated with epigenetic modifications that control changes in gene expression profiles, the impact of DNA methylation on the acquisition of the profibrotic features is still under debate [136].

\section{VitC in Stem Cells}

Scurvy is characterized by a generalized tissue disintegration, dissolution of intercellular ECM, which induces an excessive proliferation of undifferentiated cells and a reversion to a primitive form of the tissue [137]. This suggests a putative role of the VitC-collagen/ECM integrity on the control of precursor cells' proliferation. Interestingly, stromal changes (ECM depolymerization) also arise at the invasive front or in the proximity of invading neoplastic cells of aggressive tumors, where VitC mostly accumulates [138]. Furthermore, several evidence indicate that VitC stimulates the proliferation of different mesenchyme-derived cell types including osteoblasts, adipocytes, chondrocytes, and odontoblasts $[103,108,139-146]$, as well as the proliferation of immunologically relevant $\mathrm{T}$ cells [147] and hyalocytes (eye vitreous cells) [148]. Depending on the concentration used, the incubation time, and the cell type analyzed, VitC can inhibit and/or induce stem cell proliferation and/or the differentiation (Table 1). For instance, VitC safeguards the differentiation potency of bone marrow-derived multipotent mesenchymal stem cells (MSCs) stimulating their in vitro proliferation [139]. In these cells, VitC stimulates ECM secretion (collagen and glycosaminoglycan). Adipocyte stem cells (ASCs) are a heterogeneous population of MSCs that can differentiate into adipocytes, osteoblast, and chondrocytes. L-Ascorbate-2-phosphate (A2-P or Asc-2-P, $250 \mu \mathrm{M}$ ) enhances proliferation of human ASCs and induces the formation of an ASC sheet displaying abundant extracellular matrix (ECM) deposition [149]. Of note, A2-Ptreated ASCs maintain both high levels of expression of pluripotency-associated transcription factors Sox2, Oct4, and Nanog and their differentiation capabilities along adipogenic and osteogenic (mesoderm) lineages. This is highly relevant since ASCs cultivated in the absence of VitC tend to lose their stemness and pluripotency. Moreover, A2-Ptreated ASCs display enhanced hepatogenic (endoderm) and neurogenic (ectoderm) transdifferentiation capabilities under specific conditions [149]. Most relevantly, collagen synthesis appears to be required for VitC activity [149]. VitC covalently coupled to a methyl methacrylate polymer enhances the proliferation of bone marrow-derived human MSCs [143]. VitC also promotes proliferation of cardiac progenitor cells [150]. A mix of micronutrients, including VitC, transferrin, glutathione, selenite, and ethanolamine, sustains the in vitro expansion/self-renewal of mouse intestinal stem cells (ISCs) [151]. ISCs are located at the base of the intestinal crypts and, under appropriate stimuli, are able to divide and differentiate into mature epithelial cells. VitC $(40 \mu \mathrm{g} / \mathrm{ml})$ promotes the proliferation of spermatogonial stem cells (SSCs) and reduces the generation of ROS while it induces the expression of the $B c l-2$ (antiapoptotic) gene [152]. Of note, this activity is highly specific of VitC.

5.1. VitC Positively Regulates the Pluripotency Genes. VitC, like retinoic acid (vitamin A) and calciferol (vitamin D), modulates gene expression [153]. VitC induces Nanog expression in ESCs and safeguards pluripotency [154]. Similarly, VitC enhances the expression of Nanog in mouse teratocarcinoma-derived EC cells (F9) and inhibits the retinoic acid-induced differentiation of EC cells through the Janus kinase/signal transducer and activator of transcription (JAK/STAT) signaling pathway [155]. At mechanistic level, VitC induces STAT2 phosphorylation, which in turn activates Nanog transcription [155]. VitC enhances telomerase activity in periodontal ligament stem cells (PDLSCs) and upregulates the expression of extracellular matrix type-I collagen, fibronectin, integrin $\beta 1$, and the stem cell markers Oct4, Sox2, and Nanog as well as osteogenic markers Runx2, $A l p$, and Ocn [156]. In hESCs, VitC induces the expression of CD30, which is a biomarker for malignant cells in Hodgkin's disease and embryonal carcinoma cells, through a dramatic loss of DNA methylation of a CpG island in the CD30 promoter [157]. Furthermore, VitC is a competitive inhibitor of adenylate cyclase [158] and thus could repress the expression of the genes controlled by the cAMP-dependent pathway [159]. The molecular mechanism(s) involved in 
TABLE 1

\begin{tabular}{|c|c|c|c|}
\hline Cell type & Effect of exogenously supplied vitamin C & Concentration & Ref. \\
\hline ASCs (adipocyte stem cells) & $\uparrow$ Proliferation & $250 \mu \mathrm{g} / \mathrm{ml}$ & [149] \\
\hline hMSCs (human mesenchymal stem cells) & $\uparrow$ Proliferation & $50 \mu \mathrm{g} / \mathrm{ml}$ & [143] \\
\hline CPC (cardiac progenitor cells) & $\uparrow$ Proliferation & $10-250 \mu \mathrm{g} / \mathrm{ml}$ & {$[150]$} \\
\hline ISCs (intestinal stem cells) & $\uparrow$ Proliferation/self-renewal & $10-250 \mu \mathrm{M}$ & [151] \\
\hline Caprine SSCs (spermatogonial stem cells) & $\uparrow$ Proliferation & $40 \mu \mathrm{M}$ & [152] \\
\hline Cord blood-derived MSCs (mesenchymal stem cells) & $\downarrow$ Proliferation & $500 \mu \mathrm{M}$ & [163] \\
\hline TBV2 ESCs & $\uparrow$ Naive state of plurypotency & $50-150 \mu \mathrm{g} / \mathrm{ml}$ & [1] \\
\hline ESCs & $\uparrow$ Naive state of plurypotency & $10-500 \mathrm{mM}$ & [3] \\
\hline Ovarian follicles & $\uparrow$ Survival & $50 \mu \mathrm{g} / \mathrm{ml}$ & [182] \\
\hline Porcine oocytes & $\uparrow$ Maturation & $50 \mu \mathrm{g} / \mathrm{ml}$ & [181] \\
\hline J1 ESCs & $\uparrow$ Pluripotency marker expression & $50 \mu \mathrm{g} / \mathrm{ml}$ & [154] \\
\hline Periodontal ligament stem cells (PDLSCs) & $\uparrow$ Telomerase activity & $20-50 \mu \mathrm{g} / \mathrm{ml}$ & [156] \\
\hline Bone marrow-derived MSCs (mesenchymal stem cells) & $\uparrow$ Osteoblastic differentiation & $50 \mu \mathrm{g} / \mathrm{ml}$ & {$[162]$} \\
\hline Cord blood-derived MSCs (mesenchymal stem cells) & $\uparrow$ Osteogenesis & $250 \mu \mathrm{M}$ & {$[163]$} \\
\hline ESCs & $\uparrow$ Osteoclastogenesis & $50 \mu \mathrm{g} / \mathrm{ml}$ & [145] \\
\hline hMSCs (human mesenchymal stem cells) & $\uparrow$ Tenogenesis & $50 \mu \mathrm{g} / \mathrm{ml}$ & [93] \\
\hline E14 ESCs & $\uparrow$ Adipocyte differentiation & $25 \mu \mathrm{g} / \mathrm{ml}$ & [165] \\
\hline C6R8 mESCs & $\uparrow$ Cardiogenesis & $10-100 \mu \mathrm{M}$ & {$[170]$} \\
\hline Fgfr $1^{-1-} \mathrm{R} 1 \mathrm{mESCs}$ & $\uparrow$ Rescue of cardiomyocyte differentiation & $10 \mu \mathrm{M}$ & {$[171]$} \\
\hline iPSCs & $\uparrow$ Cardiogenesis & $10-250 \mu \mathrm{g} / \mathrm{ml}$ & {$[150]$} \\
\hline $\mathrm{HaCaT}$ cells & $\uparrow$ Epidermal keratinocyte differentiation & $1 \mathrm{mM}$ & {$[141]$} \\
\hline Bone marrow-derived MSCs (mesenchymal stem cells) & $\uparrow$ Smooth muscle cell differentiation (SMCs) & $30 \mu \mathrm{M}$ & [169]; [168] \\
\hline Mesencephalic precursor cells & $\uparrow$ Dopaminergic neuron differentiation & $100 \mu \mathrm{M}$ & [167]; [166] \\
\hline Pre-iPSCs from MEF & $\uparrow$ Reprogramming & $25-50 \mu \mathrm{g} / \mathrm{ml}$ & [2] \\
\hline B-cells & $\uparrow$ Reprogramming & $50 \mathrm{ng} / \mathrm{ml}$ & [125] \\
\hline Porcine somatic cells & $\uparrow$ Reprogramming & $50 \mu \mathrm{g} / \mathrm{ml}$ & [179] \\
\hline MEFs & $\uparrow$ Reprogramming & $25-50 \mu \mathrm{g} / \mathrm{ml}$ & [131] \\
\hline
\end{tabular}

VitC-dependent induction of pluripotency markers are not well understood and deserve further investigation.

5.2. Impact of VitC on Stem Cell Differentiation. A vast body of evidence supports the notion that supplemental VitC improves the differentiation and maintenance of mesenchyme-derived connective tissues, including adipose tissue, cartilage, bone, and blood (Figure 3). For instance, a combination of VitC and beta-glycerophosphate promotes differentiation of mouse ESCs toward the osteoblast lineage [160]. VitC also enhances osteoblastic differentiation of adipocyte-derived progenitor cells [161]. Moreover, a combination of staphylococcal enterotoxin $\mathrm{C}$ and VitC $(50 \mu \mathrm{g} / \mathrm{ml})$ promotes osteoblastic differentiation in bone marrow-derived MSCs [162]. Furthermore, supplemental VitC $(250 \mu \mathrm{M})$ enhances osteogenesis from umbilical cord blood-derived MSCs, whereas higher VitC concentrations $(500 \mu \mathrm{M})$ reduces MSC proliferation [163]. Low levels of VitC induce osteogenic differentiation of MG-63 osteosarcoma cell line, whereas at higher doses induce apoptosis [164]. These findings are relevant considering that impaired MSC bone differentiation potential induces osteosarcoma [164]. VitC also enhances osteoclastogenesis in ESCs [145], whereas a cocktail including VitC $(25 \mu \mathrm{g} / \mathrm{ml})$, rosiglitazone, insulin, T3, dexamethasone, and indomethacin, significantly increases ESC adipocyte differentiation [165]. VitC enhances differentiation of mesencephalic precursor cells into dopaminergic neurons [166, 167]. It has been shown that VitC promotes epidermal keratinocyte differentiation and that downregulation of protein kinase $\mathrm{C}$ activity has abolished the prodifferentiating effect of VitC [141]. A mix of TGF $\beta$ and VitC $(30 \mu \mathrm{M})$ promotes differentiation of bone marrow-derived MSCs into smooth muscle cells (SMCs) $[168,169]$. VitC improves cardiac differentiation of mouse ESCs [170]. Of note, VitC promotes cardiac differentiation only when supplemented to the culture medium in a specific time window (day 2-6 differentiation) [150]. Remarkably, VitC addition at the early phases of the differentiation process overcomes the loss of cardiomyocyte differentiation ability in fibroblast growth factor receptor 1 (Fgfr1) knockout $\left(\right.$ Fgfr $\left.1^{-/-}\right)$mESCs [171]. The molecular mechanisms underlying VitC-dependent regulation of stem cell differentiation process are largely unknown. The antioxidant activity of VitC is unlikely to be the primary underlying mechanism given that other antioxidants do not induce the same phenotypic transition/differentiation process. Most likely, VitC 


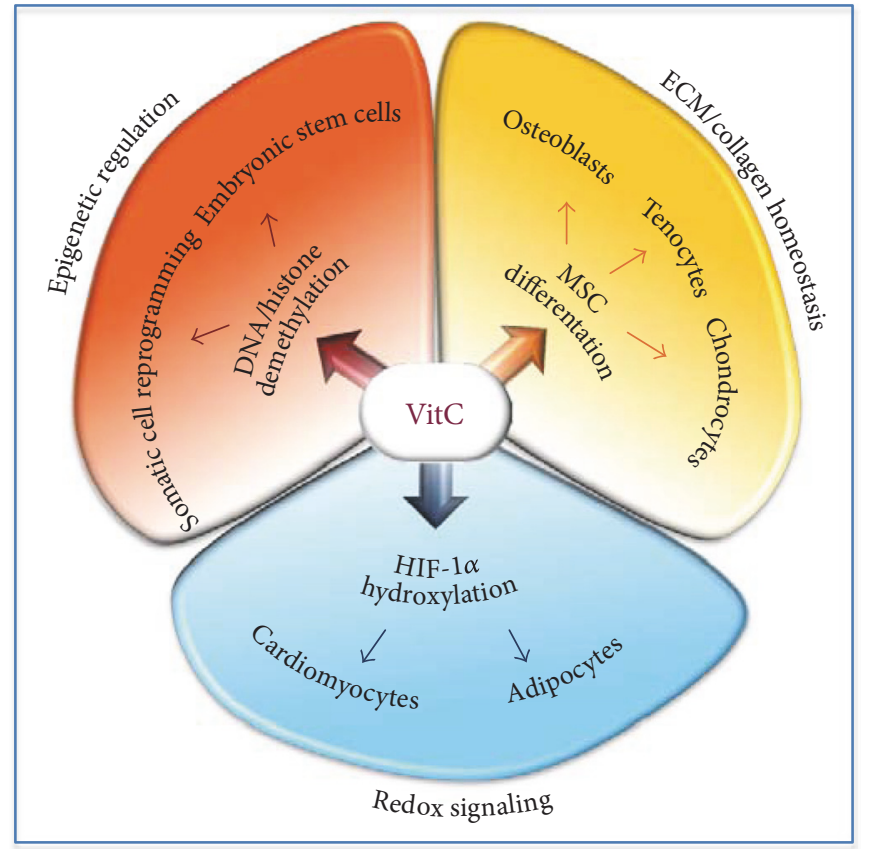

Figure 3: Molecular mechanisms underlying VitC activity on stem cells. VitC-dependent regulation of epigenetic modifications, ECM remodelling and redox balance, control embryonic stem cell self-renewal/proliferation, somatic cell reprogramming, and stem cell differentiation.

may influence stem cell differentiation by modulating DNA and histone demethylation. Accordingly, Tet1 and Tet2 double-knockout mESCs display developmental defects when injected in the mouse blastocyst [172]. Unlike wildtype mESCs, Tet 1 knockdown mESCs generate teratomas containing predominately immature glandular tissues (endoderm) surrounded by stromal cells (mesoderm) and trophoblastic giant cells, thus indicating that Tet 1 is essential for cell lineage specification [173]. Moreover, Tet1/2/3 triple knockout results in impaired differentiation potential of mESCs [174]. Furthermore, Tet2 silencing in hematopoietic stem cell impairs differentiation and alters hematopoiesis [175], whereas it induces neuroectoderm differentiation in ESCs [176]. Conversely, Tet2 overexpression sustains mESC selfrenewal while it impairs differentiation [177].

5.3. VitC in Somatic Cell Reprogramming. It is well known that the chemical composition of the medium strongly influences the epigenetic and biological properties of iPSCs [178]. Indeed, only under specific growth conditions, iPSCs acquire an ESC-like gene expression profile and epigenetic signature. In line with its ability to maintain pluripotency, supplemental VitC improves mouse and human somatic cell reprogramming [2] (Figure 3). Interestingly, addition of VitC $(50 \mathrm{ng} / \mathrm{ml})$ prevents aberrant DNA hypermethylation of the imprinted Dlk1-Dio3 gene cluster and improves the generation of fully pluripotent iPSCs [125]. VitC treatment enhances the expression of pluripotency markers (Oct4, Sox2, and Klf4) during reprogramming of porcine somatic cells through nuclear transfer [179]. Of note, other antioxidants, such as $\mathrm{N}$-acetylcysteine (NAC) and vitamin E, are unable to similarly improve cell reprograming, thus suggesting that this activity does not rely, at least primarily, on the role of VitC as antioxidant [170]. Several reports have led to the conclusion that VitC promotes the generation of induced pluripotent stem cells (iPSCs) through the activation of both histone-demethylating dioxygenases (JMJ) and TET DNA-demethylating enzymes [131]. A putative role of VitC as enhancer of the collagen synthesis/maturation has not been analyzed. Here, we speculate that somatic cells such as fibroblast may suffer VitC starvation in their nucleus, due to an excessive utilization at the level of ER (collagen synthesis). Exogenously, added VitC may thus compensate this nuclear VitC starvation, thus enhancing DNA and histone demethylation and the expression of pluripotency genes. This intriguing hypothesis may explain at least in part VitC effects on reprograming and deserves further investigation.

\section{Biotechnological and Medical Applications}

VitC is used for the in vitro production of mammalian embryos [180]. Indeed, in a narrow window of concentrations, VitC improves oocyte maturation and the subsequent development of preimplantation embryos. For instance, added at $50 \mu \mathrm{g} / \mathrm{ml}$, but not at $100 \mu \mathrm{g} / \mathrm{ml}$, VitC improves porcine oocyte maturation by increasing the cleavage rates and the total cell numbers per blastocyst and by reducing apoptotic cell death [181]. Of note, it has been established that treatment with VitC increases the pregnancy rate in pigs [179]. Furthermore, in vitro culture of ovarian follicles is an emerging tool for fertility preservation. It has been reported that VitC $(50 \mu \mathrm{g} / \mathrm{ml})$ supplementation significantly enhances the survival of early stage (primary) ovarian follicles $(<80 \mu \mathrm{m})$ cultured in alginate hydrogels, avoiding the breakdown of the follicular basement membrane [182]. In correlation, at the cellular level, VitC upregulates the expression of 
extracellular matrix (ECM) and cell adhesion molecules [182]. In adult humans, VitC accumulates in the brain, acting as antioxidant and as neuromodulator for acetylcholine and noradrenaline release [183]. In correlation, recent studies have suggested that supplemental VitC could be beneficial for the treatment of neurodegenerative disorders [184]. As a reducing agent, $\mathrm{VitC}$ is used for the treatment of methemoglobinemia [185], an autosomal recessive disorder provoked by the deficiency of methemoglobin reductase (OMIM 250800). VitC is extensively used to attenuate the symptoms of common cold [186-190]. In correlation, it has been reported that DHA, the oxidized form of VitC, inhibits the multiplication of viruses of three different families: herpes simplex virus type 1 (HSV-1), influenza virus type A, and poliovirus type 1, perhaps at the step of nucleocapsid formation occurring inside the Golgi cisternae of infected cells [191]. It has been proposed that VitC may contribute to maintain a healthy skin by altering the gene expression profile of dermal fibroblasts [192]. Indeed, VitC has modified significantly the expression of more than 250 genes in vitro cultured human dermal fibroblasts [192]. The transcriptome modifications involve mainly genes related with regulation of the cell cycle and/or mitosis, DNA replication and/or repair, lipid and glucose metabolism, cytoskeleton and ECM remodeling, and collagen biosynthesis [192]. It has also been observed that an increased intake of VitC improves tissue regeneration after surgical trauma, myocardial infarction, and thermal burns. The effect of $\mathrm{VitC}$ on cancer prevention and/or regression has been extensively studied, but the results are controversial and beyond the scope of this review. It has recently been shown that high concentrations of dehydroascorbate (DHA), that is, the oxidized form of VitC, induce oxidative stress and cell death in cancer cells [193], thus refurbishing the interest in the use of supranutritional doses of VitC as anticancer. Nonetheless, a high-dose VitC regimen as anticancer therapy has some contraindications [194] and raises some significant questions [195]. Finally, the effects of VitC on the behavior/identity of cancer stem cells have not been studied but would deserve attention.

\section{Conclusions}

An increasing number of reports reveal that VitC impacts on stem cell plasticity/identity and that this largely depends on its ability to sustain the activity of several $\mathrm{Fe}^{+2} / \alpha \mathrm{KG}$ dioxygenase enzymes, which catalyze the hydroxylation (oxidation) of different biological substrates located in specific cellular compartments. Specifically, in the nucleus, VitC modulates the activity of several DNA and histone hydroxylases, whereas in the endoplasmic reticulum, VitC acts as cofactor of collagen hydroxylases. Therefore, VitC is able to modify simultaneously both the epigenetic/gene expression profile and the extracellular matrix (microenvironment) of stem cells. In some cases, the effect of VitC activity appears to be dose dependent within a physiological concentration range. However, whether or not VitC-dependent reactions may rely on specific VitC concentrations requires further investigation, due to the current limited knowledge of the key molecular and biochemical features (i.e., expression profiles, molecular interactions, and kinetic parameters) of the enzymes and/or transporters in the different cellular compartments.

\section{Conflicts of Interest}

The authors declare that there is no conflict of interests regarding the publication of this paper.

\section{Acknowledgments}

This study was supported by the Epigenomics Flagship Project (EPIGEN) MIUR-CNR, AIRC (Grant 11599), and the Italian Ministry of Education-University-Research (Grant CTN01_00177 Cluster ALISEI_IRMI) and CARIPLO to Gabriella Minchiotti.

\section{References}

[1] C. D'Aniello, E. Habibi, F. Cermola et al., "Vitamin C and 1-proline antagonistic effects capture alternative states in the pluripotency continuum," Stem Cell Reports, vol. 8, no. 1, pp. 1-10, 2016.

[2] M. A. Esteban, T. Wang, B. Qin et al., "Vitamin C enhances the generation of mouse and human induced pluripotent stem cells," Cell Stem Cell, vol. 6, no. 1, pp. 71-79, 2010.

[3] K. Blaschke, K. T. Ebata, M. M. Karimi et al., "Vitamin C induces Tet-dependent DNA demethylation and a blastocyst-like state in ES cells," Nature, vol. 500, no. 7461, pp. 222-226, 2013.

[4] C. L. Linster and E. Van Schaftingen, "Vitamin C. Biosynthesis, recycling and degradation in mammals," The FEBS Journal, vol. 274, no. 1, pp. 1-22, 2007.

[5] A. Corti, A. F. Casini, and A. Pompella, "Cellular pathways for transport and efflux of ascorbate and dehydroascorbate," Archives of Biochemistry and Biophysics, vol. 500, no. 2, pp. 107-115, 2010.

[6] I. Savini, A. Rossi, C. Pierro, L. Avigliano, and M. V. Catani, "SVCT1 and SVCT2: key proteins for vitamin C uptake," Amino Acids, vol. 34, no. 3, pp. 347-355, 2008.

[7] C. S. Tsao, P. Y. Leung, and M. Young, "Effect of dietary ascorbic acid intake on tissue vitamin C in mice," The Journal of Nutrition, vol. 117, no. 2, pp. 291-297, 1987.

[8] K. A. Naidu, "Vitamin C in human health and disease is still a mystery? An overview," Nutrition Journal, vol. 2, no. 1, p. 7, 2003.

[9] J. Knight, K. Madduma-Liyanage, J. A. Mobley, D. G. Assimos, and R. P. Holmes, "Ascorbic acid intake and oxalate synthesis," Urolithiasis, vol. 44, no. 4, pp. 289-297, 2016.

[10] B. Frei, L. England, and B. N. Ames, "Ascorbate is an outstanding antioxidant in human blood plasma," Proceedings of the National Academy of Sciences of the United States of America, vol. 86, no. 16, pp. 6377-6381, 1989.

[11] J. M. Carcamo, A. Pedraza, O. Borquez-Ojeda, B. Zhang, R. Sanchez, and D. W. Golde, "Vitamin C is a kinase inhibitor: dehydroascorbic acid inhibits IkappaBalpha kinase beta," Molecular and Cellular Biology, vol. 24, no. 15, pp. 6645-6652, 2004.

[12] J. B. Park, "Reduction of dehydroascorbic acid by homocysteine," Biochimica et Biophysica Acta, vol. 1525, no. 1-2, pp. 173-179, 2001. 
[13] P. W. Washko, Y. Wang, and M. Levine, "Ascorbic acid recycling in human neutrophils," The Journal of Biological Chemistry, vol. 268, no. 21, pp. 15531-15535, 1993.

[14] R. Hurrell and I. Egli, "Iron bioavailability and dietary reference values," The American Journal of Clinical Nutrition, vol. 91, no. 5, pp. 1461S-1467S, 2010.

[15] N. Abbaspour, R. Hurrell, and R. Kelishadi, "Review on iron and its importance for human health," Journal of Research in Medical Sciences, vol. 19, no. 2, pp. 164-174, 2014.

[16] T. Walczyk, S. Muthayya, R. Wegmuller et al., "Inhibition of iron absorption by calcium is modest in an iron-fortified, casein- and whey-based drink in Indian children and is easily compensated for by addition of ascorbic acid," The Journal of Nutrition, vol. 144, no. 11, pp. 1703-1709, 2014.

[17] C. I. Cercamondi, I. M. Egli, C. Zeder, and R. F. Hurrell, "Sodium iron EDTA and ascorbic acid, but not polyphenol oxidase treatment, counteract the strong inhibitory effect of polyphenols from brown sorghum on the absorption of fortification iron in young women," The British Journal of Nutrition, vol. 111, no. 3, pp. 481-489, 2014.

[18] P. M. Kelley, V. Jalukar, and D. Njus, "Rate of electron transfer between cytochrome b561 and extravesicular ascorbic acid," The Journal of Biological Chemistry, vol. 265, no. 32, pp. 19409-19413, 1990.

[19] D. Su and H. Asard, "Three mammalian cytochromes b561 are ascorbate-dependent ferrireductases," The FEBS Journal, vol. 273, no. 16, pp. 3722-3734, 2006.

[20] A. T. McKie, D. Barrow, G. O. Latunde-Dada et al., "An iron-regulated ferric reductase associated with the absorption of dietary iron," Science, vol. 291, no. 5509, pp. 1755-1759, 2001.

[21] P. Lu, D. Ma, C. Yan, X. Gong, M. Du, and Y. Shi, "Structure and mechanism of a eukaryotic transmembrane ascorbatedependent oxidoreductase," Proceedings of the National Academy of Sciences of the United States of America, vol. 111, no. 5, pp. 1813-1818, 2014.

[22] D. J. Lane and D. R. Richardson, "The active role of vitamin C in mammalian iron metabolism: much more than just enhanced iron absorption!," Free Radical Biology \& Medicine, vol. 75, pp. 69-83, 2014.

[23] H. Padh, "Vitamin C: newer insights into its biochemical functions," Nutrition Reviews, vol. 49, no. 3, pp. 65-70, 1991.

[24] R. P. Hausinger, "FeII/alpha-ketoglutarate-dependent hydroxylases and related enzymes," Critical Reviews in Biochemistry and Molecular Biology, vol. 39, no. 1, pp. 21-68, 2004.

[25] Q. Lu, Y. Zhang, and J. H. Elisseeff, "Carnitine and acetylcarnitine modulate mesenchymal differentiation of adult stem cells," Journal of Tissue Engineering and Regenerative Medicine, vol. 9, no. 12, pp. 1352-1362, 2015.

[26] Y. L. He, M. M. Li, L. Y. Wu et al., "The enhanced HIF-1alpha stability induced by 5 -HMF contributes to protection against hypoxia," Molecular Medicine, vol. 20, pp. 590-600, 2014.

[27] D. Lando, D. J. Peet, J. J. Gorman, D. A. Whelan, M. L. Whitelaw, and R. K. Bruick, "FIH-1 is an asparaginyl hydroxylase enzyme that regulates the transcriptional activity of hypoxia-inducible factor," Genes \& Development, vol. 16, no. 12, pp. 1466-1471, 2002.

[28] B. Keith and M. C. Simon, "Hypoxia-inducible factors, stem cells, and cancer," Cell, vol. 129, no. 3, pp. 465-472, 2007.
[29] C. G. Yang, C. Yi, E. M. Duguid et al., "Crystal structures of DNA/RNA repair enzymes $A \mathrm{kBB}$ and $\mathrm{ABH} 2$ bound to dsDNA," Nature, vol. 452, no. 7190, pp. 961-965, 2008.

[30] C. Yi, G. Jia, G. Hou et al., "Iron-catalysed oxidation intermediates captured in a DNA repair dioxygenase," Nature, vol. 468, no. 7321, pp. 330-333, 2010.

[31] M. P. Westbye, E. Feyzi, P. A. Aas et al., "Human AlkB homolog 1 is a mitochondrial protein that demethylates 3-methylcytosine in DNA and RNA," The Journal of Biological Chemistry, vol. 283, no. 36, pp. 25046-25056, 2008.

[32] J. Ringvoll, L. M. Nordstrand, C. B. Vagbo et al., "Repair deficient mice reveal $\mathrm{mABH} 2$ as the primary oxidative demethylase for repairing $1 \mathrm{meA}$ and $3 \mathrm{meC}$ lesions in DNA," The EMBO Journal, vol. 25, no. 10, pp. 21892198, 2006.

[33] P. A. Aas, M. Otterlei, P. O. Falnes et al., "Human and bacterial oxidative demethylases repair alkylation damage in both RNA and DNA," Nature, vol. 421, no. 6925, pp. 859-863, 2003.

[34] G. Jia, C. G. Yang, S. Yang et al., "Oxidative demethylation of 3-methylthymine and 3-methyluracil in single-stranded DNA and RNA by mouse and human FTO," FEBS Letters, vol. 582, no. 23-24, pp. 3313-3319, 2008.

[35] T. Gerken, C. A. Girard, Y. C. Tung et al., "The obesityassociated FTO gene encodes a 2-oxoglutarate-dependent nucleic acid demethylase," Science, vol. 318, no. 5855, pp. 1469-1472, 2007.

[36] M. Tahiliani, K. P. Koh, Y. Shen et al., "Conversion of 5-methylcytosine to 5-hydroxymethylcytosine in mammalian DNA by MLL partner TET1," Science, vol. 324, no. 5929, pp. 930-935, 2009.

[37] Y. Xu, F. Wu, L. Tan et al., "Genome-wide regulation of $5 \mathrm{hmC}, 5 \mathrm{mC}$, and gene expression by Tet1 hydroxylase in mouse embryonic stem cells," Molecular Cell, vol. 42, no. 4, pp. 451-464, 2011.

[38] S. Ito, L. Shen, Q. Dai et al., "Tet proteins can convert 5 -methylcytosine to 5-formylcytosine and 5-carboxylcytosine," Science, vol. 333, no. 6047, pp. 1300-1303, 2011.

[39] H. Zhao and T. Chen, "Tet family of 5-methylcytosine dioxygenases in mammalian development," Journal of Human Genetics, vol. 58, no. 7, pp. 421-427, 2013.

[40] L. J. Walport, R. J. Hopkinson, M. Vollmar et al., "Human $\mathrm{UTY}(\mathrm{KDM} 6 \mathrm{C})$ is a male-specific N-methyl lysyl demethylase," The Journal of Biological Chemistry, vol. 289, no. 26, pp. 18302-18313, 2014.

[41] H. Tarhonskaya, A. M. Rydzik, I. K. Leung et al., "Nonenzymatic chemistry enables 2-hydroxyglutarate-mediated activation of 2-oxoglutarate oxygenases," Nature Communications, vol. 5, p. 3423, 2014.

[42] W. Xu, H. Yang, Y. Liu et al., "Oncometabolite 2-hydroxyglutarate is a competitive inhibitor of alphaketoglutarate-dependent dioxygenases," Cancer Cell, vol. 19, no. 1, pp. 17-30, 2011.

[43] G. Banhegyi, A. Benedetti, E. Margittai et al., "Subcellular compartmentation of ascorbate and its variation in disease states," Biochimica et Biophysica Acta, vol. 1843, no. 9, pp. 1909-1916, 2014.

[44] M. E. Meredith and J. M. May, "Regulation of embryonic neurotransmitter and tyrosine hydroxylase protein levels by ascorbic acid," Brain Research, vol. 1539, pp. 7-14, 2013. 
[45] C. Munoz-Montesino, F. J. Roa, E. Pena et al., "Mitochondrial ascorbic acid transport is mediated by a low-affinity form of the sodium-coupled ascorbic acid transporter-2," Free Radical Biology \& Medicine, vol. 70, pp. 241-254, 2014.

[46] S. Sotiriou, S. Gispert, J. Cheng et al., "Ascorbic-acid transporter Slc23a1 is essential for vitamin $\mathrm{C}$ transport into the brain and for perinatal survival," Nature Medicine, vol. 8, no. 5, pp. 514-517, 2002.

[47] C. P. Corpe, H. Tu, P. Eck et al., "Vitamin C transporter Slc23a1 links renal reabsorption, vitamin $\mathrm{C}$ tissue accumulation, and perinatal survival in mice," The Journal of Clinical Investigation, vol. 120, no. 4, pp. 1069-1083, 2010.

[48] C. Dalgard, L. Christiansen, U. Vogel, C. Dethlefsen, A. Tjonneland, and K. Overvad, "Variation in the sodiumdependent vitamin $\mathrm{C}$ transporter 2 gene is associated with risk of acute coronary syndrome among women," PLoS One, vol. 8, no. 8, p. e70421, 2013.

[49] L. Roll and A. Faissner, "Influence of the extracellular matrix on endogenous and transplanted stem cells after brain damage," Frontiers in Cellular Neuroscience, vol. 8, p. 219, 2014.

[50] M. D. Shoulders and R. T. Raines, "Collagen structure and stability," Annual Review of Biochemistry, vol. 78, pp. 929-958, 2009.

[51] E. G. Canty and K. E. Kadler, "Procollagen trafficking, processing and fibrillogenesis," Journal of Cell Science, vol. 118, no. Pt 7, pp. 1341-1353, 2005.

[52] S. Ricard-Blum, "The collagen family," Cold Spring Harbor Perspectives in Biology, vol. 3, no. 1, p. a004978, 2011.

[53] S. Murad, D. Grove, K. A. Lindberg, G. Reynolds, A. Sivarajah, and S. R. Pinnell, "Regulation of collagen synthesis by ascorbic acid," Proceedings of the National Academy of Sciences of the United States of America, vol. 78, no. 5, pp. 2879-2882, 1981.

[54] M. Chojkier, K. Houglum, J. Solis-Herruzo, and D. A. Brenner, "Stimulation of collagen gene expression by ascorbic acid in cultured human fibroblasts. A role for lipid peroxidation?" The Journal of Biological Chemistry, vol. 264, no. 28, pp. 16957-16962, 1989.

[55] B. L. Lyons and R. I. Schwarz, "Ascorbate stimulation of PAT cells causes an increase in transcription rates and a decrease in degradation rates of procollagen mRNA," Nucleic Acids Research, vol. 12, no. 5, pp. 2569-2579, 1984.

[56] B. Kim, K. M. Choi, H. S. Yim, and M. G. Lee, "Ascorbic acid enhances adipogenesis of 3T3-L1 murine preadipocyte through differential expression of collagens," Lipids in Health and Disease, vol. 12, no. 1, p. 182, 2013.

[57] A. Leask and D. J. Abraham, "TGF-beta signaling and the fibrotic response," The FASEB Journal, vol. 18, no. 7, pp. 816-827, 2004.

[58] R. B. Jakobsen, E. Ostrup, X. Zhang, T. S. Mikkelsen, and J. E. Brinchmann, "Analysis of the effects of five factors relevant to in vitro chondrogenesis of human mesenchymal stem cells using factorial design and high throughput mRNA-profiling," PLoS One, vol. 9, no. 5, p. e96615, 2014.

[59] I. Sekiya, J. T. Vuoristo, B. L. Larson, and D. J. Prockop, "In vitro cartilage formation by human adult stem cells from bone marrow stroma defines the sequence of cellular and molecular events during chondrogenesis," Proceedings of the National Academy of Sciences of the United States of America, vol. 99, no. 7, pp. 4397-4402, 2002.
[60] J. Varga and S. A. Jimenez, "Stimulation of normal human fibroblast collagen production and processing by transforming growth factor-beta," Biochemical and Biophysical Research Communications, vol. 138, no. 2, pp. 974-980, 1986.

[61] R. Raghow, A. E. Postlethwaite, J. Keski-Oja, H. L. Moses, and A. H. Kang, "Transforming growth factor-beta increases steady state levels of type I procollagen and fibronectin messenger RNAs posttranscriptionally in cultured human dermal fibroblasts," The Journal of Clinical Investigation, vol. 79, no. 4, pp. 1285-1288, 1987.

[62] R. P. Penttinen, S. Kobayashi, and P. Bornstein, "Transforming growth factor beta increases mRNA for matrix proteins both in the presence and in the absence of changes in mRNA stability," Proceedings of the National Academy of Sciences of the United States of America, vol. 85, no. 4, pp. 1105-1108, 1988.

[63] N. E. Castro, M. Kato, J. T. Park, and R. Natarajan, "Transforming growth factor beta1 (TGF-beta1) enhances expression of profibrotic genes through a novel signaling cascade and microRNAs in renal mesangial cells," The Journal of Biological Chemistry, vol. 289, no. 42, pp. 29001-29013, 2014.

[64] H. Kasai, J. T. Allen, R. M. Mason, T. Kamimura, and Z. Zhang, "TGF-betal induces human alveolar epithelial to mesenchymal cell transition (EMT)," Respiratory Research, vol. 6, p. 56, 2005.

[65] H. J. Kim, M. Y. Kim, H. Jin et al., "Peroxisome proliferatoractivated receptor $\{$ delta\} regulates extracellular matrix and apoptosis of vascular smooth muscle cells through the activation of transforming growth factor-\{beta\}1/Smad3," Circulation Research, vol. 105, no. 1, pp. 16-24, 2009.

[66] F. Verrecchia, M. L. Chu, and A. Mauviel, "Identification of novel TGF-beta /Smad gene targets in dermal fibroblasts using a combined cDNA microarray/promoter transactivation approach," The Journal of Biological Chemistry, vol. 276, no. 20, pp. 17058-17062, 2001.

[67] Q. Tao, B. Wang, Y. Zheng, X. Jiang, Z. Pan, and J. Ren, "Vitamin D prevents the intestinal fibrosis via induction of vitamin $\mathrm{D}$ receptor and inhibition of transforming growth factor-beta1/Smad3 pathway," Digestive Diseases and Sciences, vol. 60, no. 4, pp. 868-875, 2014.

[68] F. Das, A. Bera, N. Ghosh-Choudhury, H. E. Abboud, B. S. Kasinath, and G. G. Choudhury, "TGFbeta-induced deptor suppression recruits mTORC1 and not mTORC2 to enhance collagen I (alpha2) gene expression," PLoS One, vol. 9, no. 10, p. e109608, 2014.

[69] Q. Chen, C. E. Lee, B. Denard, and J. Ye, "Sustained induction of collagen synthesis by TGF-beta requires regulated intramembrane proteolysis of CREB3L1," PLoS One, vol. 9, no. 10, p. e108528, 2014.

[70] I. M. Eurlings, N. L. Reynaert, T. van den Beucken et al., "Cigarette smoke extract induces a phenotypic shift in epithelial cells; involvement of HIF1alpha in mesenchymal transition," PLoS One, vol. 9, no. 10, p. e107757, 2014.

[71] J. Myllyharju and K. I. Kivirikko, "Collagens, modifying enzymes and their mutations in humans, flies and worms," Trends in Genetics, vol. 20, no. 1, pp. 33-43, 2004.

[72] L. Knott and A. J. Bailey, "Collagen cross-links in mineralizing tissues: a review of their chemistry, function, and clinical relevance," Bone, vol. 22, no. 3, pp. 181-187, 1998.

[73] M. Yamauchi and M. Sricholpech, "Lysine post-translational modifications of collagen," Essays in Biochemistry, vol. 52, pp. 113-133, 2012. 
[74] K. L. Gorres and R. T. Raines, "Prolyl 4-hydroxylase," Critical Reviews in Biochemistry and Molecular Biology, vol. 45, no. 2, pp. 106-124, 2010.

[75] K. Juva, D. J. Prockop, G. W. Cooper, and J. W. Lash, "Hydroxylation of proline and the intracellular accumulation of a polypeptide precursor of collagen," Science, vol. 152, no. 3718, pp. 92-94, 1966.

[76] A. R. Walmsley, M. R. Batten, U. Lad, and N. J. Bulleid, "Intracellular retention of procollagen within the endoplasmic reticulum is mediated by prolyl 4-hydroxylase," The Journal of Biological Chemistry, vol. 274, no. 21, pp. 14884-14892, 1999.

[77] E. Mussini, J. J. Hutton Jr., and S. Udenfriend, "Collagen proline hydroxylase in wound healing, granuloma formation, scurvy, and growth," Science, vol. 157, no. 3791, pp. 927-929, 1967.

[78] G. Xiong, L. Deng, J. Zhu, P. G. Rychahou, and R. Xu, "Prolyl4-hydroxylase alpha subunit 2 promotes breast cancer progression and metastasis by regulating collagen deposition," BMC Cancer, vol. 14, p. 1, 2014.

[79] D. M. Gilkes, P. Chaturvedi, S. Bajpai et al., "Collagen prolyl hydroxylases are essential for breast cancer metastasis," Cancer Research, vol. 73, no. 11, pp. 3285-3296, 2013.

[80] B. V. Chakravarthi, S. S. Pathi, M. T. Goswami et al., "The miR-124-prolyl hydroxylase P4HA1-MMP1 axis plays a critical role in prostate cancer progression," Oncotarget, vol. 5, no. 16, pp. 6654-6669, 2014.

[81] N. S. Kalson, T. Starborg, Y. Lu et al., "Nonmuscle myosin II powered transport of newly formed collagen fibrils at the plasma membrane," Proceedings of the National Academy of Sciences of the United States of America, vol. 110, no. 49, pp. E4743-E4752, 2013.

[82] A. Page-McCaw, A. J. Ewald, and Z. Werb, "Matrix metalloproteinases and the regulation of tissue remodelling," Nature Reviews. Molecular Cell Biology, vol. 8, no. 3, pp. 221-233, 2007.

[83] J. Heino, "Cellular signaling by collagen-binding integrins," Advances in Experimental Medicine and Biology, vol. 819, pp. 143-155, 2014.

[84] B. Leitinger and E. Hohenester, "Mammalian collagen receptors," Matrix Biology, vol. 26, no. 3, pp. 146-155, 2007.

[85] R. J. Lebbink, T. de Ruiter, J. Adelmeijer et al., "Collagens are functional, high affinity ligands for the inhibitory immune receptor LAIR-1," The Journal of Experimental Medicine, vol. 203, no. 6, pp. 1419-1425, 2006.

[86] L. A. Flynn, A. R. Blissett, E. P. Calomeni, and G. Agarwal, "Inhibition of collagen fibrillogenesis by cells expressing soluble extracellular domains of DDR1 and DDR2," Journal of Molecular Biology, vol. 395, no. 3, pp. 533-543, 2010.

[87] D. Zeng, D. B. Ou, T. Wei et al., "Collagen/beta(1) integrin interaction is required for embryoid body formation during cardiogenesis from murine induced pluripotent stem cells," BMC Cell Biology, vol. 14, p. 5, 2013.

[88] K. R. Levental, H. Yu, L. Kass et al., "Matrix crosslinking forces tumor progression by enhancing integrin signaling," Cell, vol. 139, no. 5, pp. 891-906, 2009.

[89] D. E. Discher, D. J. Mooney, and P. W. Zandstra, "Growth factors, matrices, and forces combine and control stem cells," Science, vol. 324, no. 5935, pp. 1673-1677, 2009.

[90] M. S. Samuel, J. I. Lopez, E. J. McGhee et al., “Actomyosinmediated cellular tension drives increased tissue stiffness and beta-catenin activation to induce epidermal hyperplasia and tumor growth," Cancer Cell, vol. 19, no. 6, pp. 776-791, 2011.

[91] D. T. Butcher, T. Alliston, and V. M. Weaver, "A tense situation: forcing tumour progression," Nature Reviews. Cancer, vol. 9, no. 2, pp. 108-122, 2009.

[92] M. Egeblad, M. G. Rasch, and V. M. Weaver, "Dynamic interplay between the collagen scaffold and tumor evolution," Current Opinion in Cell Biology, vol. 22, no. 5, pp. 697-706, 2010.

[93] M. Iannone, M. Ventre, L. Formisano, L. Casalino, E. J. Patriarca, and P. A. Netti, "Nanoengineered surfaces for focal adhesion guidance trigger mesenchymal stem cell selforganization and tenogenesis," Nano Letters, vol. 15, no. 3, pp. 1517-1525, 2015.

[94] F. Chowdhury, Y. Li, Y. C. Poh, T. Yokohama-Tamaki, N. Wang, and T. S. Tanaka, "Soft substrates promote homogeneous self-renewal of embryonic stem cells via downregulating cell-matrix tractions," PLoS One, vol. 5, no. 12, p. e15655, 2010.

[95] A. J. Engler, S. Sen, H. L. Sweeney, and D. E. Discher, "Matrix elasticity directs stem cell lineage specification," Cell, vol. 126, no. 4, pp. 677-689, 2006.

[96] D. M. Gilkes, S. Bajpai, C. C. Wong et al., "Procollagen lysyl hydroxylase 2 is essential for hypoxia-induced breast cancer metastasis," Molecular Cancer Research, vol. 11, no. 5, pp. 456-466, 2013.

[97] D. M. Gilkes, S. Bajpai, P. Chaturvedi, D. Wirtz, and G. L. Semenza, "Hypoxia-inducible factor 1 (HIF-1) promotes extracellular matrix remodeling under hypoxic conditions by inducing P4HA1, P4HA2, and PLOD2 expression in fibroblasts," The Journal of Biological Chemistry, vol. 288, no. 15, pp. 10819-10829, 2013.

[98] J. Liu, Y. Tan, H. Zhang et al., "Soft fibrin gels promote selection and growth of tumorigenic cells," Nature Materials, vol. 11, no. 8, pp. 734-741, 2012.

[99] Y. Tan, A. Tajik, J. Chen et al., "Matrix softness regulates plasticity of tumour-repopulating cells via H3K9 demethylation and Sox2 expression," Nature Communications, vol. 5, p. 4619, 2014.

[100] L. E. Stephens, A. E. Sutherland, I. V. Klimanskaya et al., "Deletion of beta 1 integrins in mice results in inner cell mass failure and peri-implantation lethality," Genes \& Development, vol. 9, no. 15, pp. 1883-1895, 1995.

[101] S. Li, D. Harrison, S. Carbonetto et al., "Matrix assembly, regulation, and survival functions of laminin and its receptors in embryonic stem cell differentiation," The Journal of Cell Biology, vol. 157, no. 7, pp. 1279-1290, 2002.

[102] Y. Hayashi, M. K. Furue, T. Okamoto et al., "Integrins regulate mouse embryonic stem cell self-renewal," Stem Cells, vol. 25, no. 12, pp. 3005-3015, 2007.

[103] H. Sato, M. Takahashi, H. Ise et al., "Collagen synthesis is required for ascorbic acid-enhanced differentiation of mouse embryonic stem cells into cardiomyocytes," Biochemical and Biophysical Research Communications, vol. 342, no. 1, pp. 107-112, 2006.

[104] A. J. Zhu, I. Haase, and F. M. Watt, "Signaling via beta1 integrins and mitogen-activated protein kinase determines human epidermal stem cell fate in vitro," Proceedings of the National Academy of Sciences of the United States of America, vol. 96, no. 12, pp. 6728-6733, 1999. 
[105] L. S. Campos, D. P. Leone, J. B. Relvas et al., "Beta1 integrins activate a MAPK signalling pathway in neural stem cells that contributes to their maintenance," Development, vol. 131, no. 14, pp. 3433-3444, 2004.

[106] D. A. Williams, M. Rios, C. Stephens, and V. P. Patel, "Fibronectin and VLA-4 in haematopoietic stem cellmicroenvironment interactions," Nature, vol. 352, no. 6334, pp. 438-441, 1991.

[107] A. I. Alford, K. M. Kozloff, and K. D. Hankenson, "Extracellular matrix networks in bone remodeling," The International Journal of Biochemistry \& Cell Biology, vol. 65, pp. 20-31, 2015.

[108] Y. Maehata, S. Takamizawa, S. Ozawa et al., "Type III collagen is essential for growth acceleration of human osteoblastic cells by ascorbic acid 2-phosphate, a long-acting vitamin C derivative," Matrix Biology, vol. 26, no. 5, pp. 371-381, 2007.

[109] D. Docheva, C. Popov, P. Alberton, and A. Aszodi, "Integrin signaling in skeletal development and function," Birth Defects Research. Part C, Embryo Today, vol. 102, no. 1, pp. 13-36, 2014.

[110] F. Gattazzo, A. Urciuolo, and P. Bonaldo, "Extracellular matrix: a dynamic microenvironment for stem cell niche," Biochimica et Biophysica Acta, vol. 1840, no. 8, pp. 2506-2519, 2014.

[111] W. Reik, W. Dean, and J. Walter, "Epigenetic reprogramming in mammalian development," Science, vol. 293, no. 5532, pp. 1089-1093, 2001.

[112] A. Inoue and Y. Zhang, "Replication-dependent loss of 5-hydroxymethylcytosine in mouse preimplantation embryos," Science, vol. 334, no. 6053, p. 194, 2011.

[113] J. P. Ross, K. N. Rand, and P. L. Molloy, "Hypomethylation of repeated DNA sequences in cancer," Epigenomics, vol. 2, no. 2, pp. 245-269, 2010.

[114] M. Esteller, "Epigenetics in cancer," The New England Journal of Medicine, vol. 358, no. 11, pp. 1148-1159, 2008.

[115] J. Li, Q. Huang, F. Zeng et al., "The prognostic value of global DNA hypomethylation in cancer: a meta-analysis," PLoS One, vol. 9, no. 9, p. e106290, 2014.

[116] H. Bierne, M. Hamon, and P. Cossart, "Epigenetics and bacterial infections," Cold Spring Harbor Perspectives in Medicine, vol. 2, no. 12, p. a010272, 2012.

[117] M. N. Dang, R. Buzzetti, and P. Pozzilli, "Epigenetics in autoimmune diseases with focus on type 1 diabetes," Diabetes/Metabolism Research and Reviews, vol. 29, no. 1, pp. 8-18, 2013.

[118] P. Stenvinkel, M. Karimi, S. Johansson et al., "Impact of inflammation on epigenetic DNA methylation - a novel risk factor for cardiovascular disease?" Journal of Internal Medicine, vol. 261, no. 5, pp. 488-499, 2007.

[119] L. J. Buro-Auriemma, J. Salit, N. R. Hackett et al., "Cigarette smoking induces small airway epithelial epigenetic changes with corresponding modulation of gene expression," Human Molecular Genetics, vol. 22, no. 23, pp. 4726-4738, 2013.

[120] I. Smolarek, E. Wyszko, A. M. Barciszewska et al., "Global DNA methylation changes in blood of patients with essential hypertension," Medical Science Monitor, vol. 16, no. 3, pp. CR149-CR155, 2010.

[121] E. A. Minor, B. L. Court, J. I. Young, and G. Wang, "Ascorbate induces ten-eleven translocation (Tet) methylcytosine dioxygenase-mediated generation of 5-hydroxymethylcytosine," The Journal of Biological Chemistry, vol. 288, no. 19, pp. 13669-13674, 2013.

[122] S. O. Sajadian, C. Tripura, F. S. Samani et al., "Vitamin C enhances epigenetic modifications induced by 5 -azacytidine and cell cycle arrest in the hepatocellular carcinoma cell lines HLE and Huh7," Clinical Epigenetics, vol. 8, no. 1, p. $46,2016$.

[123] S. Comes, M. Gagliardi, N. Laprano et al., "L-proline induces a mesenchymal-like invasive program in embryonic stem cells by remodeling $\mathrm{H} 3 \mathrm{~K} 9$ and H3K36 methylation," Stem Cell Reports, vol. 1, no. 4, pp. 307-321, 2013.

[124] T. L. Chung, R. M. Brena, G. Kolle et al., "Vitamin C promotes widespread yet specific DNA demethylation of the epigenome in human embryonic stem cells," Stem Cells, vol. 28, no. 10, pp. 1848-1855, 2010.

[125] M. Stadtfeld, E. Apostolou, F. Ferrari et al., "Ascorbic acid prevents loss of Dlk1-Dio3 imprinting and facilitates generation of all-iPS cell mice from terminally differentiated B cells," Nature Genetics, vol. 44, no. 4, pp. 398-405, 2012.

[126] C. A. Doege, K. Inoue, T. Yamashita et al., "Early-stage epigenetic modification during somatic cell reprogramming by Parp1 and Tet2," Nature, vol. 488, no. 7413, pp. 652655, 2012.

[127] Y. Gao, J. Chen, K. Li et al., "Replacement of Oct4 by Tet1 during iPSC induction reveals an important role of DNA methylation and hydroxymethylation in reprogramming," Cell Stem Cell, vol. 12, no. 4, pp. 453-469, 2013.

[128] J. Chen, H. Liu, J. Liu et al., "H3K9 methylation is a barrier during somatic cell reprogramming into iPSCs," Nature Genetics, vol. 45, no. 1, pp. 34-42, 2013.

[129] T. Wang, K. Chen, X. Zeng et al., “The histone demethylases Jhdm $1 \mathrm{a} / 1 \mathrm{~b}$ enhance somatic cell reprogramming in a vitamin-C-dependent manner," Cell Stem Cell, vol. 9, no. 6, pp. 575-587, 2011.

[130] X. Hu, L. Zhang, S. Q. Mao et al., "Tet and TDG mediate DNA demethylation essential for mesenchymal-to-epithelial transition in somatic cell reprogramming," Cell Stem Cell, vol. 14, no. 4, pp. 512-522, 2014.

[131] J. Chen, L. Guo, L. Zhang et al., "Vitamin C modulates TET1 function during somatic cell reprogramming," Nature Genetics, vol. 45, no. 12, pp. 1504-1509, 2013.

[132] T. P. Gu, F. Guo, H. Yang et al., "The role of Tet3 DNA dioxygenase in epigenetic reprogramming by oocytes," Nature, vol. 477, no. 7366, pp. 606-610, 2011.

[133] R. M. Kohli and Y. Zhang, "TET enzymes, TDG and the dynamics of DNA demethylation," Nature, vol. 502, no. 7472, pp. 472-479, 2013.

[134] C. G. Lian, Y. Xu, C. Ceol et al., "Loss of 5hydroxymethylcytosine is an epigenetic hallmark of melanoma," Cell, vol. 150, no. 6, pp. 1135-1146, 2012.

[135] C. Perez, N. Martinez-Calle, J. I. Martin-Subero et al., “TET2 mutations are associated with specific 5-methylcytosine and 5 -hydroxymethylcytosine profiles in patients with chronic myelomonocytic leukemia," PLoS One, vol. 7, no. 2, p. e31605, 2012.

[136] R. Neary, C. J. Watson, and J. A. Baugh, "Epigenetics and the overhealing wound: the role of DNA methylation in fibrosis," Fibrogenesis \& Tissue Repair, vol. 8, no. 1, p. 18, 2015. 
[137] E. Cameron, L. Pauling, and B. Leibovitz, "Ascorbic acid and cancer: a review," Cancer Research, vol. 39, no. 3, pp. 663-681, 1979.

[138] N. J. Chinoy, "Ascorbic acid levels in mammalian tissues and its metabolic significance," Comparative Biochemistry and Physiology A, Comparative Physiology, vol. 42, no. 4, pp. 945-952, 1972.

[139] K. M. Choi, Y. K. Seo, H. H. Yoon et al., "Effect of ascorbic acid on bone marrow-derived mesenchymal stem cell proliferation and differentiation," Journal of Bioscience and Bioengineering, vol. 105, no. 6, pp. 586-594, 2008.

[140] F. J. Alcain and M. I. Buron, "Ascorbate on cell growth and differentiation," Journal of Bioenergetics and Biomembranes, vol. 26, no. 4, pp. 393-398, 1994.

[141] I. Savini, M. V. Catani, A. Rossi, G. Duranti, G. Melino, and L. Avigliano, "Characterization of keratinocyte differentiation induced by ascorbic acid: protein kinase $\mathrm{C}$ involvement and vitamin C homeostasis," The Journal of Investigative Dermatology, vol. 118, no. 2, pp. 372-379, 2002.

[142] E. Arakawa, K. Hasegawa, J. Irie et al., "L-ascorbic acid stimulates expression of smooth muscle-specific markers in smooth muscle cells both in vitro and in vivo," Journal of Cardiovascular Pharmacology, vol. 42, no. 6, pp. 745-751, 2003.

[143] Y. Wang, A. Singh, P. Xu, M. A. Pindrus, D. J. Blasioli, and D. L. Kaplan, "Expansion and osteogenic differentiation of bone marrow-derived mesenchymal stem cells on a vitamin C functionalized polymer," Biomaterials, vol. 27, no. 17, pp. 3265-3273, 2006.

[144] T. M. Lin, J. L. Tsai, S. D. Lin, C. S. Lai, and C. C. Chang, "Accelerated growth and prolonged lifespan of adipose tissue-derived human mesenchymal stem cells in a medium using reduced calcium and antioxidants," Stem Cells and Development, vol. 14, no. 1, pp. 92-102, 2005.

[145] M. Tsuneto, H. Yamazaki, M. Yoshino, T. Yamada, and S. Hayashi, "Ascorbic acid promotes osteoclastogenesis from embryonic stem cells," Biochemical and Biophysical Research Communications, vol. 335, no. 4, pp. 1239-1246, 2005.

[146] Y. Yan, W. Zeng, S. Song et al., "Vitamin C induces periodontal ligament progenitor cell differentiation via activation of ERK pathway mediated by PELP1," Protein \& Cell, vol. 4, no. 8, pp. 620-627, 2013.

[147] M. J. Huijskens, M. Walczak, N. Koller et al., "Technical advance: ascorbic acid induces development of doublepositive T cells from human hematopoietic stem cells in the absence of stromal cells," Journal of Leukocyte Biology, vol. 96, no. 6, pp. 1165-1175, 2014.

[148] F. Sommer, K. Kobuch, F. Brandl et al., "Ascorbic acid modulates proliferation and extracellular matrix accumulation of hyalocytes," Tissue Engineering, vol. 13, no. 6, pp. 1281-1289, 2007.

[149] J. Yu, Y. K. Tu, Y. B. Tang, and N. C. Cheng, "Stemness and transdifferentiation of adipose-derived stem cells using L-ascorbic acid 2-phosphate-induced cell sheet formation," Biomaterials, vol. 35, no. 11, pp. 3516-3526, 2014.

[150] N. Cao, Z. Liu, Z. Chen et al., "Ascorbic acid enhances the cardiac differentiation of induced pluripotent stem cells through promoting the proliferation of cardiac progenitor cells," Cell Research, vol. 22, no. 1, pp. 219-236, 2012.

[151] M. S. Mohamed, Y. Chen, and C. L. Yao, "A serum-free medium developed for in vitro expansion of murine intestinal stem cells," Biotechnology Journal, vol. 9, no. 7, pp. 962-970, 2014.

[152] J. Wang, H. Cao, X. Xue et al., "Effect of vitamin C on growth of caprine spermatogonial stem cells in vitro," Theriogenology, vol. 81, no. 4, pp. 545-555, 2014.

[153] D. M. Shin, J. I. Ahn, K. H. Lee, Y. S. Lee, and Y. S. Lee, "Ascorbic acid responsive genes during neuronal differentiation of embryonic stem cells," Neuroreport, vol. 15, no. 12, pp. 1959-1963, 2004.

[154] Y. Gao, L. Yang, L. Chen et al., "Vitamin C facilitates pluripotent stem cell maintenance by promoting pluripotency gene transcription," Biochimie, vol. 95, no. 11, pp. 21072113, 2013.

[155] H. Wu, Y. Wu, Z. Ai et al., "Vitamin C enhances Nanog expression via activation of the JAK/STAT signaling pathway," Stem Cells, vol. 32, no. 1, pp. 166-176, 2014.

[156] F. Wei, C. Qu, T. Song et al., "Vitamin C treatment promotes mesenchymal stem cell sheet formation and tissue regeneration by elevating telomerase activity," Journal of Cellular Physiology, vol. 227, no. 9, pp. 3216-3224, 2012.

[157] T. L. Chung, J. P. Turner, N. Y. Thaker et al., "Ascorbate promotes epigenetic activation of CD30 in human embryonic stem cells," Stem Cells, vol. 28, no. 10, pp. 1782-1793, 2010.

[158] F. Kaya, S. Belin, G. Diamantidis, and M. Fontes, "Ascorbic acid is a regulator of the intracellular CAMP concentration: old molecule, new functions?” FEBS Letters, vol. 582, no. 25-26, pp. 3614-3618, 2008.

[159] S. Belin, F. Kaya, S. Burtey, and M. Fontes, "Ascorbic acid and gene expression: another example of regulation of gene expression by small molecules?" Current Genomics, vol. 11, no. 1, pp. 52-57, 2010.

[160] L. D. Buttery, S. Bourne, J. D. Xynos et al., "Differentiation of osteoblasts and in vitro bone formation from murine embryonic stem cells," Tissue Engineering, vol. 7, no. 1, pp. 89-99, 2001.

[161] A. Gupta, D. T. Leong, H. F. Bai, S. B. Singh, T. C. Lim, and D. W. Hutmacher, "Osteo-maturation of adiposederived stem cells required the combined action of vitamin D3, beta-glycerophosphate, and ascorbic acid," Biochemical and Biophysical Research Communications, vol. 362, no. 1, pp. 17-24, 2007.

[162] X. C. Wan, C. P. Liu, M. Li et al., "Staphylococcal enterotoxin $\mathrm{C}$ injection in combination with ascorbic acid promotes the differentiation of bone marrow-derived mesenchymal stem cells into osteoblasts in vitro," Biochemical and Biophysical Research Communications, vol. 373, no. 4, pp. 488-492, 2008.

[163] N. K. Mekala, R. R. Baadhe, S. Rao Parcha, and Y. Prameela Devi, "Enhanced proliferation and osteogenic differentiation of human umbilical cord blood stem cells by L-ascorbic acid, in vitro," Current Stem Cell Research \& Therapy, vol. 8, no. 2, pp. 156-162, 2013.

[164] M. T. Valenti, M. Zanatta, L. Donatelli et al., "Ascorbic acid induces either differentiation or apoptosis in MG-63 osteosarcoma lineage," Anticancer Research, vol. 34, no. 4, pp. 1617-1627, 2014.

[165] I. Cuaranta-Monroy, Z. Simandi, Z. Kolostyak et al., "Highly efficient differentiation of embryonic stem cells into adipocytes by ascorbic acid," Stem Cell Research, vol. 13, no. 1, pp. 88-97, 2014.

[166] D. H. Yu, K. H. Lee, J. Y. Lee et al., "Changes of gene expression profiles during neuronal differentiation of central 
nervous system precursors treated with ascorbic acid," Journal of Neuroscience Research, vol. 78, no. 1, pp. 29-37, 2004.

[167] J. Yan, L. Studer, and R. D. McKay, “Ascorbic acid increases the yield of dopaminergic neurons derived from basic fibroblast growth factor expanded mesencephalic precursors," Journal of Neurochemistry, vol. 76, no. 1, pp. 307-311, 2001.

[168] Y. Narita, A. Yamawaki, H. Kagami, M. Ueda, and Y. Ueda, "Effects of transforming growth factor-beta 1 and ascorbic acid on differentiation of human bone-marrow-derived mesenchymal stem cells into smooth muscle cell lineage," Cell and Tissue Research, vol. 333, no. 3, pp. 449-459, 2008.

[169] E. Arakawa, K. Hasegawa, N. Yanai, M. Obinata, and Y. Matsuda, "A mouse bone marrow stromal cell line, TBR-B, shows inducible expression of smooth muscle-specific genes," FEBS Letters, vol. 481, no. 2, pp. 193-196, 2000.

[170] T. Takahashi, B. Lord, P. C. Schulze et al., "Ascorbic acid enhances differentiation of embryonic stem cells into cardiac myocytes," Circulation, vol. 107, no. 14, pp. 1912-1916, 2003.

[171] E. Crescini, L. Gualandi, D. Uberti, C. Prandelli, M. Presta, and P. Dell'Era, "Ascorbic acid rescues cardiomyocyte development in Fgfr1(-/-) murine embryonic stem cells," Biochimica et Biophysica Acta, vol. 1833, no. 1, pp. 140-147, 2013.

[172] M. M. Dawlaty, A. Breiling, T. Le et al., "Combined deficiency of Tet 1 and Tet 2 causes epigenetic abnormalities but is compatible with postnatal development," Developmental Cell, vol. 24, no. 3, pp. 310-323, 2013.

[173] K. P. Koh, A. Yabuuchi, S. Rao et al., "Tet1 and Tet2 regulate 5-hydroxymethylcytosine production and cell lineage specification in mouse embryonic stem cells," Cell Stem Cell, vol. 8, no. 2, pp. 200-213, 2011.

[174] M. M. Dawlaty, A. Breiling, T. Le et al., "Loss of Tet enzymes compromises proper differentiation of embryonic stem cells," Developmental Cell, vol. 29, no. 1, pp. 102-111, 2014.

[175] K. Moran-Crusio, L. Reavie, A. Shih et al., "Tet2 loss leads to increased hematopoietic stem cell self-renewal and myeloid transformation," Cancer Cell, vol. 20, no. 1, pp. 11-24, 2011.

[176] T. Langlois, B. da Costa Reis Monte-Mor, G. Lenglet et al., "TET2 deficiency inhibits mesoderm and hematopoietic differentiation in human embryonic stem cells," Stem Cells, vol. 32, no. 8, pp. 2084-2097, 2014.

[177] L. Norman, P. Tarrant, and T. Chevassut, "TET2 inhibits differentiation of embryonic stem cells but does not overcome methylation-induced gene silencing," Bone Marrow Research, vol. 2014, p. 986571, 2014.

[178] K. Takahashi and S. Yamanaka, "Induction of pluripotent stem cells from mouse embryonic and adult fibroblast cultures by defined factors," Cell, vol. 126, no. 4, pp. 663-676, 2006.

[179] Y. Huang, X. Tang, W. Xie et al., "Vitamin C enhances in vitro and in vivo development of porcine somatic cell nuclear transfer embryos," Biochemical and Biophysical Research Communications, vol. 411, no. 2, pp. 397-401, 2011.

[180] M. Castillo-Martin, S. Bonet, R. Morato, and M. Yeste, "Supplementing culture and vitrification-warming media with l-ascorbic acid enhances survival rates and redox status of IVP porcine blastocysts via induction of GPX1 and SOD1 expression," Cryobiology, vol. 68, no. 3, pp. 451-458, 2014.

[181] M. Kere, C. Siriboon, N. W. Lo, N. T. Nguyen, and J. C. Ju, "Ascorbic acid improves the developmental competence of porcine oocytes after parthenogenetic activation and somatic cell nuclear transplantation," The Journal of Reproduction and Development, vol. 59, no. 1, pp. 78-84, 2013.

[182] D. Tagler, Y. Makanji, T. Tu et al., "Promoting extracellular matrix remodeling via ascorbic acid enhances the survival of primary ovarian follicles encapsulated in alginate hydrogels," Biotechnology and Bioengineering, vol. 111, no. 7, pp. 1417-1429, 2014.

[183] A. Dalpiaz, B. Pavan, S. Vertuani et al., "Ascorbic and 6-Brascorbic acid conjugates as a tool to increase the therapeutic effects of potentially central active drugs," European Journal of Pharmaceutical Sciences, vol. 24, no. 4, pp. 259-269, 2005.

[184] E. Sawicka-Glazer and S. J. Czuczwar, "Vitamin C: a new auxiliary treatment of epilepsy?" Pharmacological Reports, vol. 66, no. 4, pp. 529-533, 2014.

[185] J. Deeny, E. T. Murdock, and J. J. Rogan, "Familial idiopathic methaemoglobinaemia: treatment with ascorbic acid," British Medical Journal, vol. 1, no. 4301, pp. 721-723, 1943.

[186] H. Hemila and E. Chalker, "Vitamin C for preventing and treating the common cold," Cochrane Database of Systematic Reviews, vol. 1, no. 6, article CD000980, 2013.

[187] C. S. Johnston, G. M. Barkyoumb, and S. S. Schumacher, "Vitamin C supplementation slightly improves physical activity levels and reduces cold incidence in men with marginal vitamin C status: a randomized controlled trial," Nutrients, vol. 6, no. 7, pp. 2572-2583, 2014.

[188] L. Pauling, "The significance of the evidence about ascorbic acid and the common cold," Proceedings of the National Academy of Sciences of the United States of America, vol. 68, no. 11 , pp. $2678-2681,1971$.

[189] R. M. Douglas and H. Hemila, "Vitamin C for preventing and treating the common cold," PLoS Medicine, vol. 2, no. 6, article e168, 2005.

[190] Y. Kim, H. Kim, S. Bae et al., "Vitamin C is an essential factor on the anti-viral immune responses through the production of interferon-alpha/beta at the initial stage of influenza A virus (H3N2) infection," Immune network, vol. 13, no. 2, pp. 70-74, 2013.

[191] M. Uozaki, K. Ikeda, K. Tsujimoto et al., "Antiviral effects of dehydroascorbic acid," Experimental and Therapeutic Medicine, vol. 1, no. 6, pp. 983-986, 2010.

[192] T. L. Duarte, M. S. Cooke, and G. D. Jones, “Gene expression profiling reveals new protective roles for vitamin $\mathrm{C}$ in human skin cells," Free Radical Biology \& Medicine, vol. 46, no. 1, pp. 78-87, 2009.

[193] J. Yun, E. Mullarky, C. Lu et al., "Vitamin C selectively kills KRAS and BRAF mutant colorectal cancer cells by targeting GAPDH," Science, vol. 350, no. 6266, pp. 1391-1396, 2015.

[194] Z. Z. Zhang, E. E. Lee, J. Sudderth et al., "Glutathione depletion, pentose phosphate pathway activation, and hemolysis in erythrocytes protecting cancer cells from vitamin C-induced oxidative stress," The Journal of Biological Chemistry, vol. 291, no. 44, pp. 22861-22867, 2016.

[195] J. van der Reest and E. Gottlieb, "Anti-cancer effects of vitamin C revisited," Cell Research, vol. 26, no. 3, pp. 269-270, 2016. 

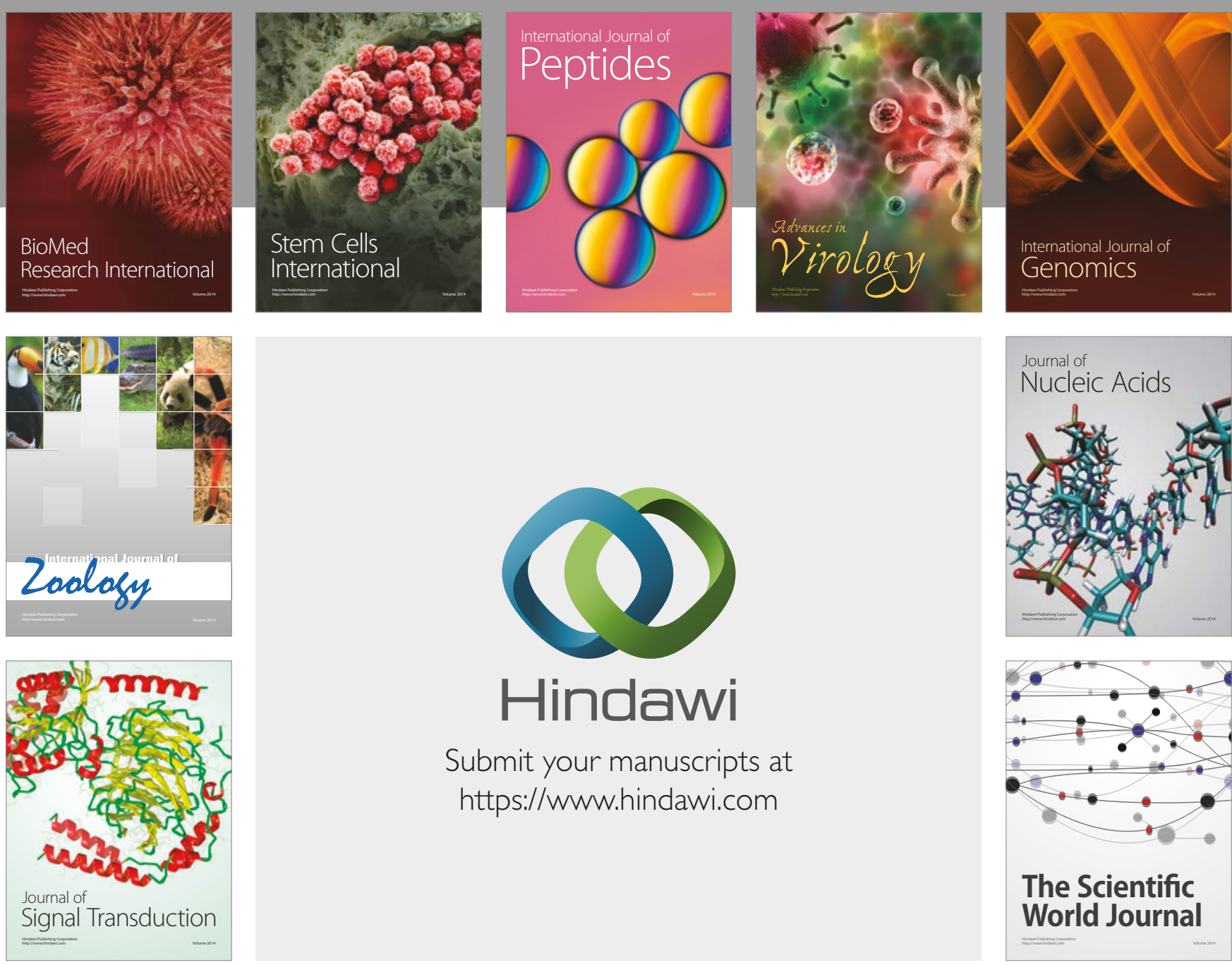

Submit your manuscripts at

https://www.hindawi.com
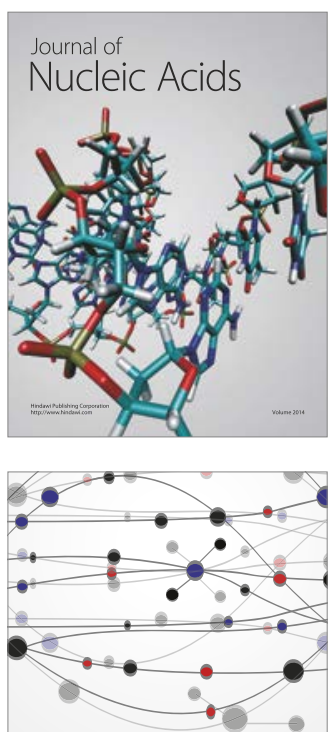

The Scientific World Journal

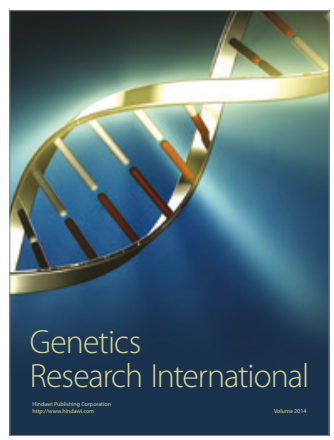

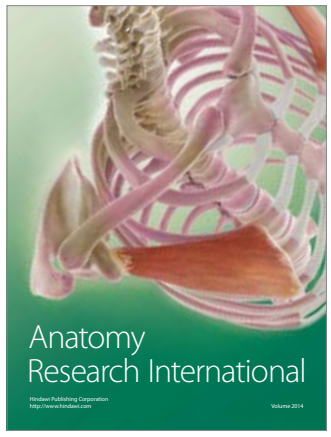

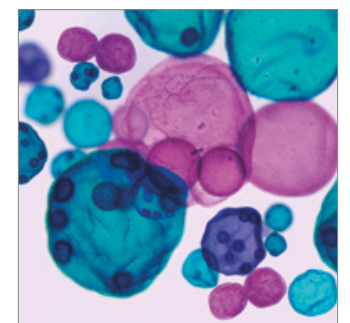

International Journal of Microbiology
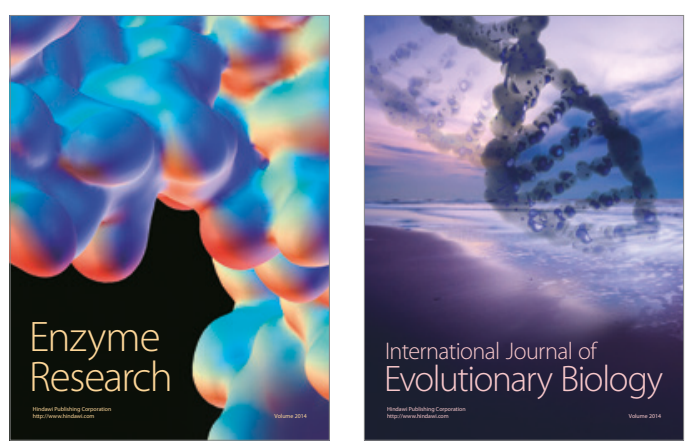
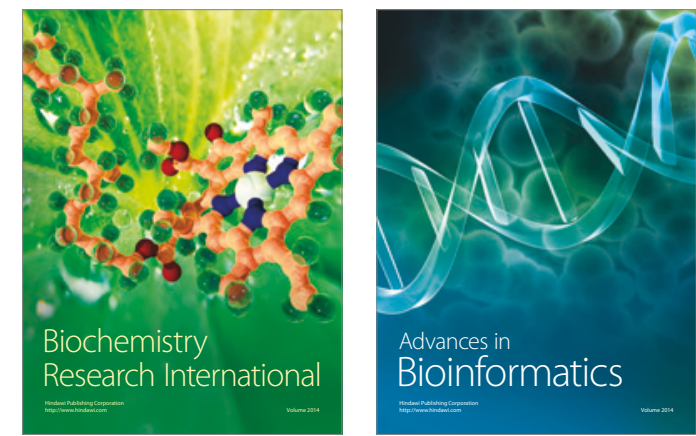

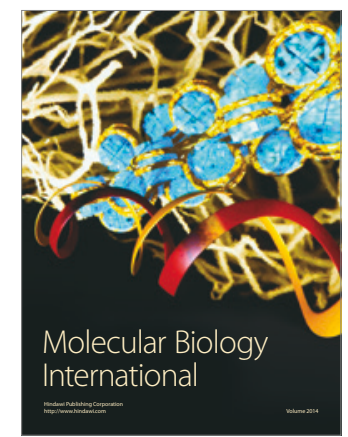

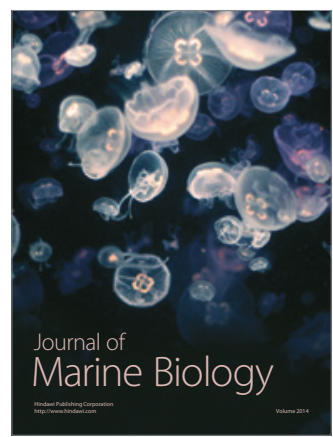

